NBER WORKING PAPER SERIES

THIS TIME IS NOT SO DIFFERENT:

INCOME DYNAMICS DURING THE COVID-19 RECESSION

Brian D. Bell

Nicholas Bloom

Jack Blundell

Working Paper 28871

http://www.nber.org/papers/w28871

\author{
NATIONAL BUREAU OF ECONOMIC RESEARCH \\ 1050 Massachusetts Avenue \\ Cambridge, MA 02138 \\ May 2021
}

We thank Luigi Pistaferri for comments and advice throughout. This work contains statistical data from ONS which is Crown Copyright. The use of the ONS statistical data in this work does not imply the endorsement of the ONS in relation to the interpretation or analysis of the statistical data. This work uses research datasets which may not exactly reproduce National Statistics aggregates. This work uses results originally presented in Bell, Bloom, and Blundell (2021). The views expressed herein are those of the authors and do not necessarily reflect the views of the National Bureau of Economic Research.

NBER working papers are circulated for discussion and comment purposes. They have not been peer-reviewed or been subject to the review by the NBER Board of Directors that accompanies official NBER publications.

(C) 2021 by Brian D. Bell, Nicholas Bloom, and Jack Blundell. All rights reserved. Short sections of text, not to exceed two paragraphs, may be quoted without explicit permission provided that full credit, including $\odot$ notice, is given to the source. 
This Time is Not so Different: Income Dynamics During the COVID-19 Recession

Brian D. Bell, Nicholas Bloom, and Jack Blundell

NBER Working Paper No. 28871

May 2021

JEL No. J0

\begin{abstract}
$\underline{\text { ABSTRACT }}$ individual earnings dynamics.

Brian D. Bell

Centre for Economic Performance

London School of Economics

Houghton Street

London WC2A 2AE

United Kingdom

b.bell1@1se.ac.uk

Nicholas Bloom

Stanford University

Department of Economics

579 Serra Mall

Stanford, CA 94305-6072

and NBER

nbloom@stanford.edu

Jack Blundell

Stanford University

jackblundell@stanford.edu
\end{abstract}

We use a UK employer-employee administrative earnings dataset to investigate the response of earnings and hours to business cycles. Exploiting our long panel of data from 1975 to 2020 we find wide heterogeneity in the exposure of different types of workers to aggregate shocks. Employees who are younger, male, lower-skilled, non-union, and working in smaller private sector firms show the largest earnings response to recessions. The qualitative patterns of earnings changes across workers observed in the COVID-19 recession are broadly as predicted using the previously estimated exposures and size of the GDP shock. This suggests the COVID-19 recession in terms of its impact responses was relatively similar to those that have gone before, but the GDP shock was far larger in absolute size. Compared to aggregate shocks, we find a relatively small role of firm-specific shocks, suggesting macro shocks play an outsized role in 


\title{
This Time is Not so Different: Income Dynamics During the COVID-19 Recession*
}

\author{
Brian Bell, Nicholas Bloomªnd Jack Blundell ${ }^{\S}$
}

May 24, 2021

\begin{abstract}
We use a UK employer-employee administrative earnings dataset to investigate the response of earnings and hours to business cycles. Exploiting our long panel of data from 1975 to 2020 we find wide heterogeneity in the exposure of different types of workers to aggregate shocks. Employees who are younger, male, lower-skilled, non-union, and working in smaller private sector firms show the largest earnings response to recessions. The qualitative patterns of earnings changes across workers observed in the COVID-19 recession are broadly as predicted using the previously estimated exposures and size of the GDP shock. This suggests the COVID19 recession in terms of its impact responses was relatively similar to those that have gone before, but the GDP shock was far larger in absolute size. Compared to aggregate shocks, we find a relatively small role of firm-specific shocks, suggesting macro shocks play an outsized role in individual earnings dynamics.
\end{abstract}

\section{Introduction}

The UK has recently made available its earnings microdata covering the initial part of the COVID19 pandemic, offering an early window into the impact likely to be seen in the US and other countries. This data spans from 1975 to 2020, providing earnings data over four recessions. Before examining the impact of recessions on earnings, we start by analyzing some of the trends in earnings

*We thank Luigi Pistaferri for comments and advice throughout. This work contains statistical data from ONS which is Crown Copyright. The use of the ONS statistical data in this work does not imply the endorsement of the ONS in relation to the interpretation or analysis of the statistical data. This work uses research datasets which may not exactly reproduce National Statistics aggregates. This work uses results originally presented in Bell, Bloom, and Blundell (2021).

${ }^{\dagger}$ King's Business School / CEP

$\ddagger$ Stanford University / CEP

$\S$ Stanford University / CEP 
dynamics seen in the UK to set the broader picture for analyzing the impact of the COVID-19 pandemic. As in the US, earnings inequality has been rising in the UK for both men and women, particularly in the top $1 \%$, while earnings volatility for men has been falling but is flat for women.

Following the broad investigation of inequality, volatility and mobility, we narrow our focus onto the responsiveness of earnings and hours to aggregate and firm-level shocks. We estimate an aggregate earnings GDP beta of 0.38 , meaning that a $1 \%$ increase in GDP is associated with a $0.38 \%$ increase in earnings. However, we provide evidence of strong asymmetries, with this elasticity rising to 0.73 in expansionary periods and falling close to zero in recessions. Leveraging data on hours, we find a relatively large hours response to GDP fluctuations, with an elasticity estimate of 0.16. Again, there are asymmetries, but these are in the opposite direction to earnings, with hours responses coming mostly from recessionary periods.

A unique aspect of our data is that it is updated frequently, meaning that it already includes earnings data for 2020. This allows us to provide some early evidence on the earnings response to the COVID recession. For administrative-quality earnings data, which is often associated with a significant time delay, this is unusual. Our core results suggest that both on aggregate and in cross-group comparisons, the earnings hit is close to what we would have predicted given the size of the shock - in that sense, this time is not so different. This striking pattern is displayed in Figure 1, where we compare the estimated effect of the COVID-19 shock on the earnings of different groups to the predicted effect based on historically-estimated earnings-GDP betas and the size of the shock. 
Figure 1: Predicted and actual COVID-19 earnings effects

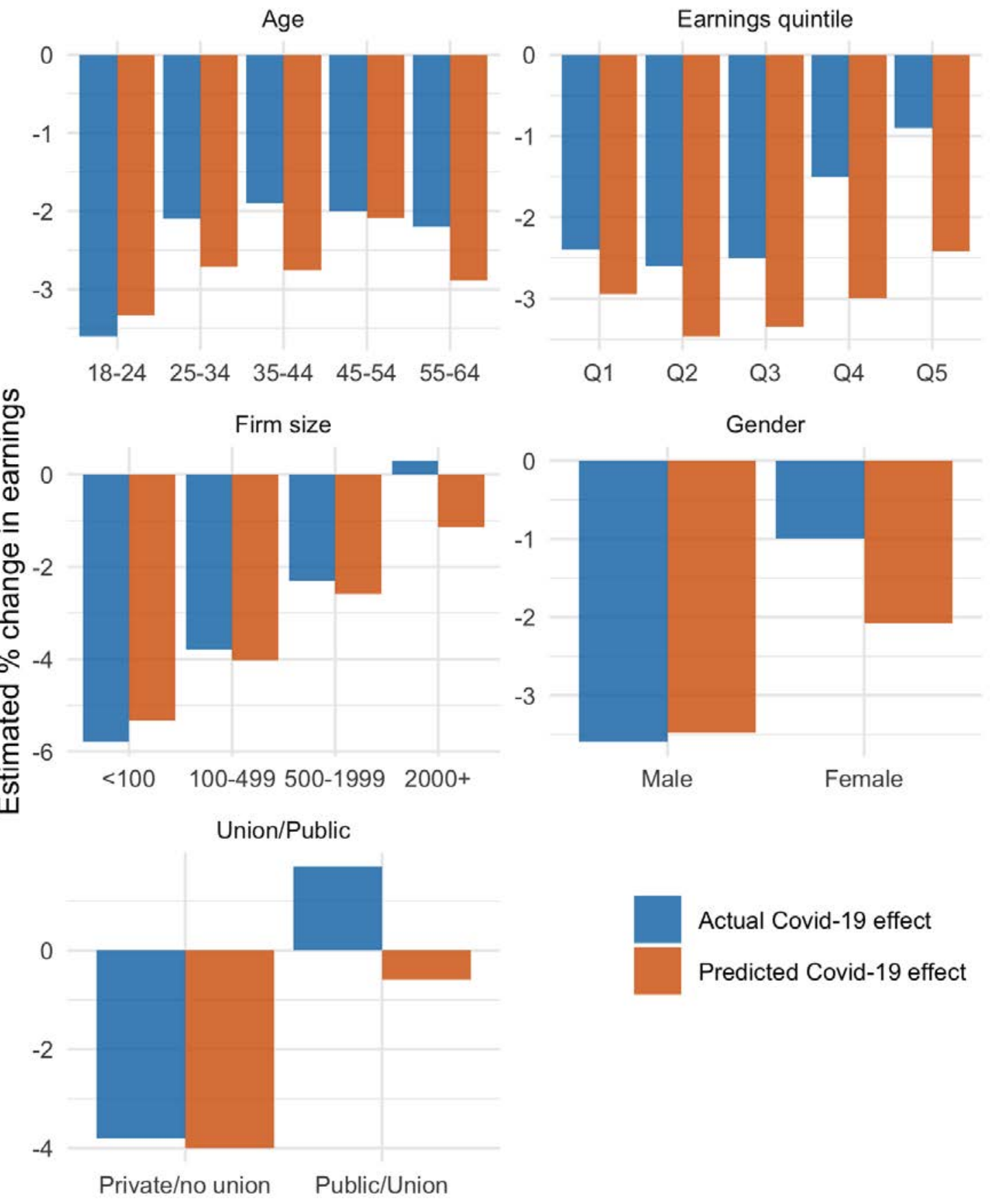

Notes: Comparison of estimated actual COVID-19 effect on earnings and predicted effect using data 1975-2020, other than firm size which uses 2002-2020. Assumes GDP drop of 7.4\%, which is the the annual change in monthly GDP index as of March 2020.

Source: Regression results reported in Tables 3 and 5

This article is structured as follows. In Section 2 we discuss the primary datasets used. In 
Section 3 we present a series of descriptive patterns in income inequality, volatility and mobility. In Section 4 we exploit the long time dimension of our dataset to estimate the effect of aggregate economic shocks on workers' earnings and hours. We show that there is substantial heterogeneity across workers in their response to aggregate shocks and that the patterns are generally consistent with those found in the United States (Guvenen, Schulhofer-Wohl, et al., 2017). We also expand on the comparison of the COVID-19 shock and previous shocks, and inspect the effect of the UK's furlough scheme. Finally, we report estimates of the impact of firm-level shocks on earnings before concluding in Section 5.

\section{Data}

\subsection{Annual Survey of Hours and Earnings}

Our analysis requires data with detailed information on earnings and a long panel component. For the UK the only available dataset which meets these requirements is the Annual Survey of Hours and Earnings (ASHE), formerly named the New Earnings Survey (NES). ${ }^{12}$ This is the premier source of earnings information in the UK and forms the basis for many official wage statistics. It is a $1 \%$ sample of all employees, with a panel structure which makes it possible to follow workers over time. The study has been used extensively for research on inequality, and due to its detailed earnings information also for studies on wage rigidities (Nickell and Quintini, 2003; Elsby, Shin, and Solon, 2016). Firm identifiers have also been included, allowing it to be used for studies on the role of within and between-firm inequality (Schaefer and Singleton, 2019).

The panel dataset is available back to 1975 and is administered by the Office for National Statistics (ONS). Workers enter the sample frame by having a particular pair of digits at the end of their National Insurance Number (NIN), the UK equivalent of a Social Security Number, assigned to all workers upon labor market entry. Surveyers then identify the employer(s) of these individuals by Her Majesty's Revenue and Customs (HMRC) Pay As You Earn (PAYE) system, the UK government's income tax withholding system. This takes place each January.

Survey forms are then typically sent to employers requesting information on the worker(s) in the sampling frame who are identified as working for that employer in the PAYE records. Employers complete the forms using information from payroll records. For larger employers, much of the process is automated, with surveyors accessing payroll records and extracting information directly.

\footnotetext{
${ }^{1}$ Office for National Statistics. (2020). Annual Survey of Hours and Earnings, 1997-2020: Secure Access. [data collection]. 17th Edition. UK Data Service. SN: 6689, http://doi.org/10.5255/UKDA-SN-6689-16. Office for National Statistics. (2017). New Earnings Survey Panel Dataset, 1975-2016: Secure Access. [data collection]. 7th Edition. UK Data Service. SN: 6706, http://doi.org/10.5255/UKDA-SN-6706-7.

${ }^{2}$ The dataset is also sometimes called the New Earnings Survey Panel Dataset. Throughout the paper, we refer to the dataset as ASHE.
} 
The survey covers both the public and private sectors, and as it is administered via employers it excludes the self-employed, who constitute approximately 15\% of UK employment as of 2019. The survey delivers useable information on 140,000 to 180,000 employees each year. Workers are followed throughout their entire working lives, so years can be combined to form a panel dataset.

The variables consistently available throughout the entire period include detailed wage and hours information for a snapshot period in April. Wages are broken down into standard and overtime pay. Studies using ASHE tend to use either weekly or hourly wages. From 1998 ASHE also provides a measure of annual earnings over the previous April-April tax year. This variable refers only to annual earnings at the worker's current employer, so needs to be used with caution as for workers who move employers, this will cover only part of their annual salary. ${ }^{3}$ Wages in ASHE are not top-coded.

Earnings are deflated by CPI and given in 2018 GBP unless otherwise noted. To retain anonymity, where percentiles or percentile-based statistics are reported, data are binned into groups of 10 individuals and each individual is assigned the group mean.

This data misses out some important components of income. Most importantly, as pay refers only to pay received within a particular reference period, for the most part this will miss bonus pay. These payments are in theory captured by asking employers to proportionately allocate any incentive or bonus payments made outside the survey week, provided the incentive was related to work in that week. However, a large share of bonuses do not appear to be captured in the weekly data. Bell and Van Reenen (2014) show that bonuses are an important component of the top 1\% inequality, and this issue is covered in more detail in Bell, Bloom, and Blundell (2021).

The hours data refer to the total hours the employee worked in the reference week, according to the employer. The hours variable is more accurate for hourly-paid workers. As is typical in administrative employer-reported hours data, there is significant bunching at a handful of discrete thresholds representing standard contracts. For some workers, these will not reflect the true hours worked over the week. As discussed in Ritchie (2005), hours for non-manual workers are consistently lower in this data than as reported in household surveys.

The worker's three-digit occupation code is also available, along with age and sex. This is used to assign a skill level to each worker using the UK government's skill level classifications. ${ }^{4}$ This is possible only for years 2011 onwards. Employer identifiers, which allow the linking of other ONS and external data are available from 2002 onwards. ${ }^{5}$ We also use a variable indicating whether

\footnotetext{
${ }^{3}$ This issue is covered in more detail in Bell, Bloom, and Blundell (2021).

${ }^{4}$ Home Office Immigration Rules Appendix J: Codes of practice for Tier 2 Sponsors, Tier 5 Sponsors and employers of work permit holders.

${ }^{5}$ The 'entref' ID variable refers to the 'enterprise', which is close to the typical definition of a 'firm' and is the standard grouping of organizations used by the ONS. Formally, an enterprise is the smallest combination of legal units (based on VAT of PAYE records) that is an organizational unit producing goods or services, benefiting from a degree of autonomy in decision-making, especially for the allocation of current resources. Enterprises carry out one or more
} 
or not a worker's wage is covered by a collective agreement, which we will use as a measure of unionization. ${ }^{6}$ There is also an indicator for whether or not a worker is in the public sector.

Whilst the information in ASHE is thought to be of exceptionally high quality, not all workers are covered. Firstly, employees that work at businesses outside of the interdepartmental business register (IDBR) are excluded as they cannot be identified in the tax administration records. These are typically very small businesses who fall below the Value Added Tax (VAT) threshold. Currently, the threshold is set to a turnover of GBP 85,000 (USD 110,000). Relatedly, employees who earn below the National Insurance Lower Earnings Limit (LEL) are not subject to PAYE tax withholding, so will not be in the PAYE system. The current LEL is set to $120 \mathrm{GBP}$, or approximately 150 USD per week. This means that a number of the very lowest-paid workers are omitted from the survey. A minimum-wage earner working 15 hours per week in the UK makes 130 GBP, so the majority of missing workers will be those working fewer than 15 hours a week on the minimum wage. This is a small group, and will disproportionately be made up of women, who are more likely to work part time. The ONS estimates that biases caused by omitting these missing firms and employees are likely to be small, though it is difficult to precisely quantify their extent. Workers falling below the LEL are not necessary excluded. As Ritchie (2005) points out "because tax records are held over, even if no tax is paid in a particular year, rather more are included than might be expected".

The two issues above are due to the administrative process of constructing the sampling frame. However, a comparison of sample sizes in ASHE to employment count estimates suggests there to be non-negligible non-response issues. Appendix Figure 11 compares the number of jobs appearing in ASHE to $1 \%$ of the estimated aggregate number, provided by the ONS and drawn from a variety of data sources. Between $30 \%$ and $40 \%$ of jobs are missing for most periods. We see that the share missing is broadly stable from 1975-1996, then falls in the late 1990s before stabilizing again from 2000. It is not clear why this fall in coverage occurs, and this pattern means we must be cautious when interpreting changes which occur in the mid-late 1990s.

There are two points at which coverage falls below 50\%. The first come in 2007 and 2008. In these years, there was a temporary reduction in the sample size, which the ONS stated was due to 'work priority' reasons. Reductions were "targeted on those industries that exhibit the least variation in their earnings patterns". This means that we should interpret the estimates for these two years with caution, particularly when looking at earnings changes. The second comes in 2020, which is attributable for the timing of the survey, during the first lockdown of the COVID-19 crisis. The disruption caused by the crisis likely led to a number of firms not entering their information.

activities at one or more locations and may be sole legal units.

${ }^{6}$ For those covered by collective agreements at the national, sectoral or regional level, this is coded as 1 . For those covered by collective agreements at the organizational or workplace level, this is coded as 0 . The share of workers covered by unions according to this variable declines from just over half in 1975 to around a quarter in the most recent years, in line with government statistics on trade union membership. 
At the worker level, the cause of non-response is primarily that the employee has moved employers between the point at which employers are identified in the tax data and the point at which the survey is sent out (Ritchie, 2005). It can also be that employers have retained previous workers in their PAYE records, despite the fact that they no longer work there. Bird (2004) reports that in $2003,12 \%$ of responses stated that the employee in question had left the business. This means that job movers are under-sampled in ASHE. The second type of non-response is at the firm level. Businesses are legally obliged to comply, though it is not clear how well this is enforced in practice. It is possible to identify in the data a small number of cases which are strongly suggestive of complete firm non-response. Ritchie (2005) estimates that return rates on the ASHE forms are typically $95 \% .^{7}$

When an individual is missing, it is not possible to observe why this is. This makes the dataset inappropriate for studying movements into or out of employment. Missing individuals could be unemployed, have left the labor market or migrated abroad, be self-employed or be missing due to the reasons described above. Missingness is non-random, with those who change jobs more frequently more likely to become missing, along with women, low earners and workers at smaller firms.

Up to and including 2003, very little changed in the methodology underlying the survey. In 2004, the NES formally became ASHE. The most important change for the current paper is that the latter attempts to improve on the tracing of workers who change jobs just before the survey period. Originally, the NES finds workers from tax records in January or February, and bases their form send-out addresses on this. From 2004, ASHE used an additional later date to identify new leavers / joiners. ASHE also included more small business which did not operate within the standard tax withholding (PAYE) system. This was done using a supplemental survey. Finally, there is some imputation of aspects of earnings and hours in the dataset, but this does not apply to our main earnings and hours variables. Given these changes, we ought to be cautious when interpreting any trend breaks around this time.

For Section 3 of this paper in which we inspect trends in inequality, volatility and mobility, we restrict our analysis to workers aged 25-55. As is standard when using ASHE data, we exclude those whose pay is affected by absence in the reference week. Some papers using this data exclude those on training / apprenticeship wages. In practice, the age restriction means that this applies to very few workers in our sample, and irrespective of this, in our view a study of workers' wages over time should account for these earnings.

Unless otherwise noted we drop a number of workers at the bottom of each year's earnings distribution, in order to select only those with reasonable labor market attachment. For years 1999 onwards, we drop those with weekly earnings below $7 \mathrm{x}$ the minimum wage, corresponding to one

\footnotetext{
${ }^{7}$ Limited weights are available for the most recent years, but for consistency over time we do not use these.
} 
days work for a low-wage worker. For the years before then, we scale the 1999 minimum wage by median real earnings growth to calculate a pseudo minimum wage. Our threshold is $7 \mathrm{x}$ this value.

Throughout the paper we refer to 'raw', 'residual' and 'permanent' log earnings. Raw log earnings corresponds to real weekly earnings above the threshold discussed in the previous paragraph, unless specified otherwise. Residual log earnings is the residual of raw log earnings regressed on individual age dummies for each year and each gender separately. Permanent log earnings in year $t$ is the average of year $t-2, t-1$ and $t$ earnings, including any earnings that fall below the threshold. Averaged earnings across these years are then residualized on age within year and gender. To be assigned a value for permanent earnings, individuals must have above-threshold earnings for at least two of the three years.

We draw on three samples, CS (cross-sectional), LX (longitudinal) and H (heterogeneity). The CS sample is made up of all those with earnings above the lower threshold. The LX sample is a subset of this group for whom we also observe above-threshold earnings for years $t+1$ and $t+5$, so that we can produce statistics based on one and five year changes. The $\mathrm{H}$ sample is a further subset, for whom we are able to build a measure of permanent income in $t-1$ as discussed above. ${ }^{8}$

Table 1 shows descriptive statistics for the CS sample by year. Panel (a) shows mean real weekly earnings for men and women, the share of female workers in the sample and the age distribution. Panel (b) shows earnings percentiles.

Tables 11 and 12 in the Appendix show summary statistics for the LX and $\mathrm{H}$ samples respectively. Unsurprisingly given the issue of missingness, conditioning on having 1 and 5 year earnings changes leads to a substantial drop in the sample size, as does having enough data to construct permanent income in the H sample. Comparing LX to CS, we lose around half the sample. The LX sample is younger by construction, similar in income and slightly less female. Younger workers and those in the middle age bracket (36-45) are more likely to remain in the LX sample. Older individuals fall out of the sample when we require earnings at $t+1$ and $t+5$ due to the age restriction. Relative to the LX sample, the $\mathrm{H}$ sample is older. Younger workers are mechanically omitted due to a lack of earnings history. Given this, it is unsurprising that the $\mathrm{H}$ sample have higher earnings than both LX and CS.

\subsection{Firm-level data}

Our firm-level data comes from two sources. Firstly, we use an ONS dataset called the Annual Respondents Database (ARD), ${ }^{9}$ which is constructed from the Annual Business Inquiry (ABI) survey.

\footnotetext{
${ }^{8}$ When presenting results from the $\mathrm{LX}$ and $\mathrm{H}$ samples using only one-year forward differences, we do not require the sample to also have five-year. This means that the LX and $\mathrm{H}$ sample differs depending on whether one or five-year changes are being presented.

${ }^{9}$ Office for National Statistics. Virtual Microdata Laboratory (VML), University of the West of England, Bristol. (2017). Annual Respondents Database X, 1998-2015: Secure Access. [data collection]. 4th Edition. Office for
} 
Table 1: Descriptive Statistics for CS sample by year

\begin{tabular}{lccccccr}
\hline Year & Obs & Fem inc & Male inc & \% Fem & \multicolumn{3}{c}{ Age } \\
& & & & & $\%$ 25-35 & $\%$ 36-45 & \% 46-55 \\
\hline 1975 & 93,082 & 309 & 599 & 36 & 36 & 30 & 34 \\
1980 & 102,697 & 318 & 619 & 39.1 & 37.4 & 31.1 & 31.4 \\
1985 & 99,449 & 362 & 681 & 41.3 & 37 & 33.7 & 29.3 \\
1990 & 114,668 & 455 & 826 & 43.7 & 38.6 & 33.4 & 28 \\
1995 & 115,072 & 494 & 841 & 46.4 & 38.6 & 31.5 & 29.9 \\
2000 & 110,415 & 560 & 931 & 47.5 & 33.5 & 35.2 & 31.2 \\
2005 & 114,028 & 648 & 1,024 & 49.8 & 31.4 & 36.9 & 31.7 \\
2010 & 119,105 & 670 & 1,017 & 50.9 & 32 & 33.5 & 34.4 \\
2015 & 121,036 & 634 & 914 & 51.6 & 34.1 & 30.4 & 35.4 \\
2020 & 82,270 & 669 & 906 & 52 & 34 & 31.6 & 34.4 \\
\hline
\end{tabular}

(a) Earnings and demographics

\begin{tabular}{ccccccccccr}
\hline Year & \multicolumn{1}{c}{ Percentile } & \multicolumn{1}{c}{ } \\
& 1 & 5 & 10 & 25 & 50 & 75 & 90 & 95 & 99 & 99.9 \\
\hline 1975 & 85 & 145 & 193 & 326 & 470 & 623 & 792 & 925 & 1,305 & 2,186 \\
1980 & 67 & 128 & 179 & 328 & 472 & 633 & 813 & 964 & 1,403 & 2,217 \\
1985 & 66 & 125 & 187 & 343 & 506 & 690 & 921 & 1,107 & 1,649 & 2,977 \\
1990 & 75 & 147 & 220 & 394 & 594 & 836 & 1,122 & 1,382 & 2,225 & 4,411 \\
1995 & 72 & 144 & 220 & 393 & 597 & 859 & 1,164 & 1,436 & 2,313 & 4,822 \\
2000 & 84 & 168 & 246 & 429 & 650 & 942 & 1,293 & 1,624 & 2,766 & 5,628 \\
2005 & 105 & 191 & 275 & 467 & 704 & 1,038 & 1,451 & 1,840 & 3,246 & 6,235 \\
2010 & 105 & 190 & 270 & 461 & 700 & 1,046 & 1,467 & 1,877 & 3,291 & 6,781 \\
2015 & 103 & 184 & 250 & 426 & 649 & 965 & 1,350 & 1,717 & 2,852 & 5,465 \\
2020 & 119 & 202 & 273 & 456 & 661 & 971 & 1,358 & 1,717 & 2,828 & 5,289 \\
\hline
\end{tabular}

(b) Earnings percentiles

Notes: Summary statistics for CS sample. All earnings figures are weekly earnings in 2018 USD. Panel (a) gives mean weekly earnings, the share female and the share in each age bracket. Panel (b) gives earnings percentiles for both genders combined for each year.

Source: ASHE

We use data from 2002 to 2014, the latest year available. The survey is a census of large establishments (250 employees or more) and a stratified sample of small and medium-sized enterprises. ${ }^{10}$ Larger firms appear in the sample throughout, but smaller firms move in and out. Stratification for the smaller and medium-sized enterprises is based on industry, employment and country. We use a measure of value added at factor cost at the firm level, which is derived by the ONS from

National Statistics, [original data producer(s)]. UK Data Service. SN: 7989, http://doi.org/10.5255/UKDA-SN-7989-4

${ }^{10}$ Sampling is actually performed at the reporting unit level, which in most cases coincides with the enterprise unit level. 
reported turnover and intermediate purchases. We then form our main labor productivity measure by dividing by employment. Our employment data is drawn from the Inter-Departmental Business Register (IDBR). While this approach represents the best-quality firm-level labor productivity data available, there is likely to be measurement error. This will in part be due to mis-reported or mis-recorded information on the components of productivity, but also due to timing issues, and particularly a timing mis-match between value added and employment.

To complement the ARD, we also use company accounts data from Bureau van Dijk's FAME database. This contains company accounts data which we use to generate an alternative measure of value added, which we calculated as the sum of each firm's operating profit and total staff costs. We divide this by the number of employees in the FAME data, as reported in company accounts for that year. Again, for the reasons discussed above there will likely be measurement error in this calculation.

A further issue with the FAME productivity data is that matching FAME to ONS data is imperfect. Matching has been performed via a lookup table held by the ONS which contains entrefcompany number links for 2014-2018. For years prior to this, we backfill using the most recent entref match available. This should detect firms whether they survive to 2014 or not, though coverage becomes less reliable for earlier years. This is exacerbated by older extinct firms being dropped from the FAME database.

Companies included in FAME may be subsidiaries of one-another, or part of a parent group. In these cases, the FAME company number matches to multiple entrefs. When this occurs, we check the population and turnover figures against the Business Structure Database (BSD) ${ }^{11}$, the main business register. This allows us to identify the most likely matches in cases where there is ambiguity. This also helps exclude incorrect matches in the early part of the sample. Relative to the ARD, the disadvantage is that despite best efforts, there will be some incorrectly-matched firms. For this reason, we use ARD as our main source of firm-level information and will use FAME as an instrument, to be discussed below.

Appendix Table 9 shows the number of firms and workers in our worker-firm match sample, along with summary statistics at the firm level. Panel (a) shows this for the ARD. We see that between $31 \%$ and $40 \%$ of workers are matched to firm-level value-added measures in the ARD. ${ }^{12}$ Appendix Table 10 shows that on average, matched workers are at larger employers than in the full sample, due to the nature of the ARD sample construction. They are also higher earning, older, more likely to be male and more likely to be full-time workers.

Appendix Table 9 Panel (b) shows the equivalent information for FAME, which has lower match

\footnotetext{
${ }^{11}$ Office for National Statistics. (2019). Business Structure Database, 1997-2018: Secure Access. [data collection]. 10th Edition. UK Data Service. SN: 6697, http://doi.org/10.5255/UKDA-SN-6697-10

${ }^{12} \mathrm{~A}$ small number of public sector workers in quasi-public sector roles are matched successfully to the firm-level data.
} 
rates than the ARD. Matching is again non-random, as shown in Appendix Table 10.

\section{Descriptive patterns in Inequality, Volatility and Mobility}

To set the background for the analysis of the COVID-19 pandemic we first provide a battery of descriptive patterns covering income inequality, volatility and mobility. We provide historical context where appropriate, and refer the reader to Appendix A for more details on macroeconomic trends and labor market institutions.

\subsection{Inequality}

Much has been written on the long-term trend of rising UK wage inequality. A succinct review of inequality patterns and research contributions is provided by Hills et al. (2010), Machin (2011) and more recently in Brewer (2019). The Deaton review at the Institute for Fiscal Studies presents a thorough overview of wage inequality and how it relates to household income inequality. The patterns we show here are consistent with this existing evidence, and provide important background to the following sections on volatility and mobility.

Figure 2 shows trends in log earnings percentiles. In panel (a) we can see strong male median real wage growth throughout the 1980s, late 1990s and early 2000s. The period since the 2008 recession has been characterized by an extended decline in real wages, with only partial recovery in the final part of the sample. As will be more clearly demonstrated in the figures to follow, the period saw a widening of the wage distribution, with the greatest wage growth being felt at the top percentiles. Panel (b) shows a contrasting picture for female workers. Median wage growth has been stronger and shown more signs of recovery post-2008. While the top percentiles have growth fastest over the period as a whole for women, wage growth has occurred across the distribution.

Panels (c) and (d) demonstrate a pronounced fanning out of earnings within the top decile of the earnings distribution, with the top $0.01 \%$ of earners seeing the largest growth over the period.

Figure 3 shows trends in earnings dispersion. In panel (a), we can see the steady increase in male earnings inequality both for the parametric (2.56* standard deviation) and non-parametric (P90 - P10) measure. This increase has tapered off and gone into decline since 2010, though dispersion remains high relative to previous decades. In panel (b), we see that for women, inequality has been roughly flat or falling since the mid 1990s. Panels (c) and (d) decompose aggregate dispersion into right tail (P90 - P50) and left tail (P50 - P10) dispersion. For men, we can see that both right and left tail dispersion have contributed to the overall rise in inequality over the period. The decline in inequality felt in recent years comes entirely from the P50-P10 tail. Returning to Figure 2, we see that significant wage growth in the 10th percentile has resulted in a closing of the gap between the 
Figure 2: Change of percentiles of the log real earnings distribution

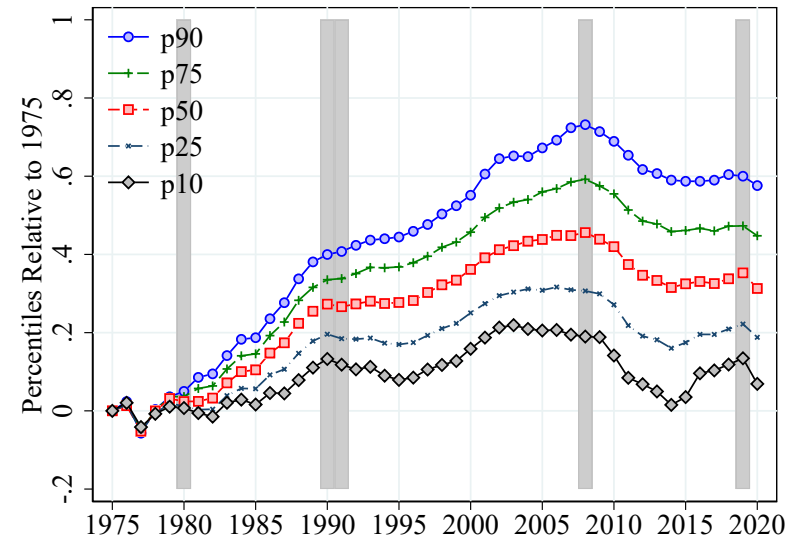

(a) Male

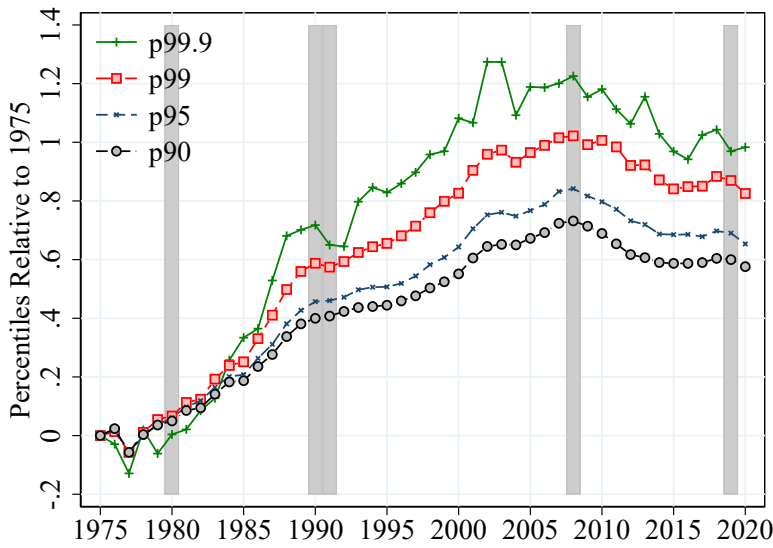

(c) Male

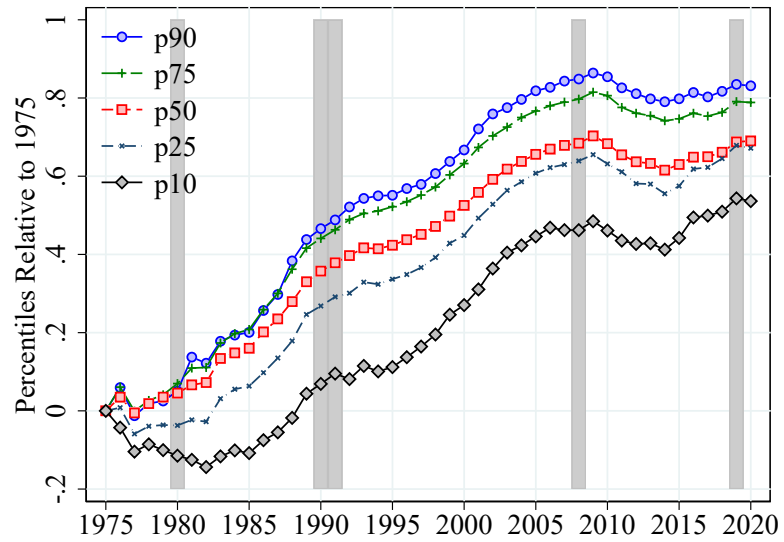

(b) Female

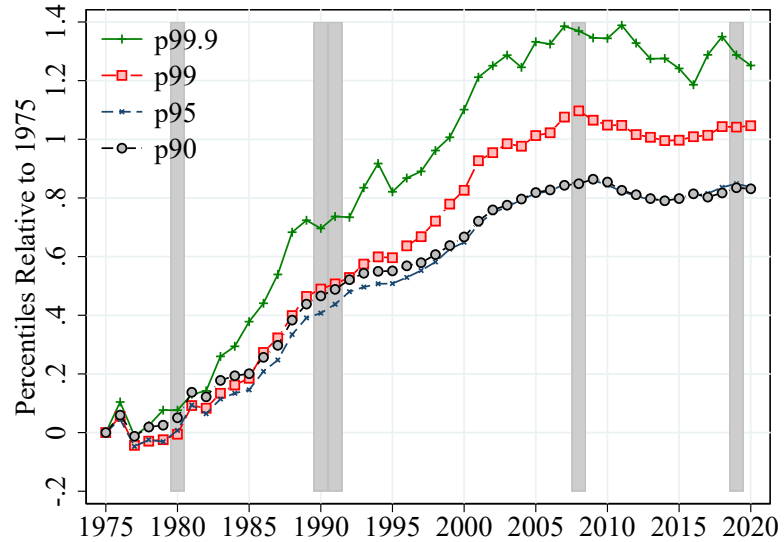

(d) Female

Notes: Raw log earnings and CS sample. All percentiles normalized to 0 in 1975. Shaded areas are recessions. Source: ASHE

lowest and average earners. For women, the picture is different. We see that the substantial rise in inequality from 1975-1995 was driven primarily by increases in P50 - P10. Since the mid 1990s, this has been in decline. P90 - P50 on the other hand has been increasing steadily throughout, up until the most recent years.

It has been argued that since its introduction in 1999 the minimum wage has successfully propped up the lower part of the earnings distribution, particularly among women. ${ }^{13}$ This is consistent with that, though the fall in female P50-P10 predates its introduction. The largest single-year increase in the minimum wage relative to average real wages came in 2016, with the introduction of the 'National Living Wage' (NLW), which was effectively a large increase in the minimum wage.

\footnotetext{
${ }^{13}$ The Low Pay Commission (LPC, 2020a) states that in 1999, 3.4\% of jobs were covered. By 2018, this had grown to $7.0 \%$.
} 
Figure 3: Log earnings dispersion

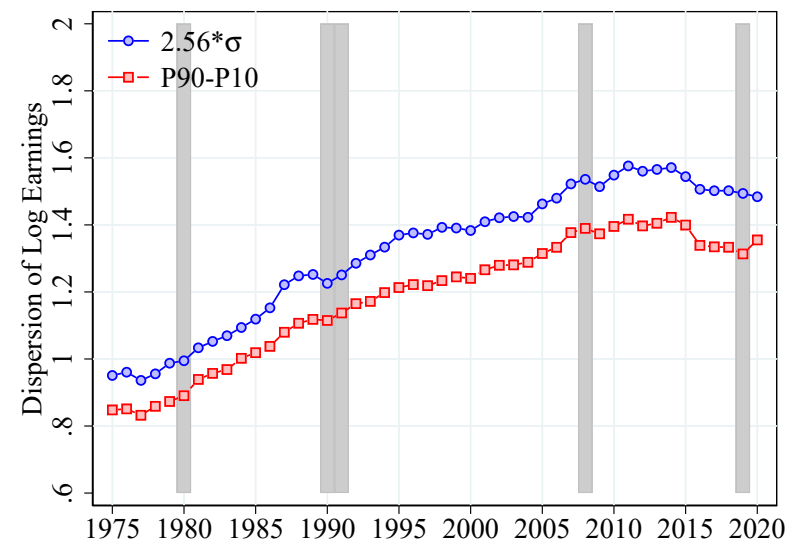

(a) Male

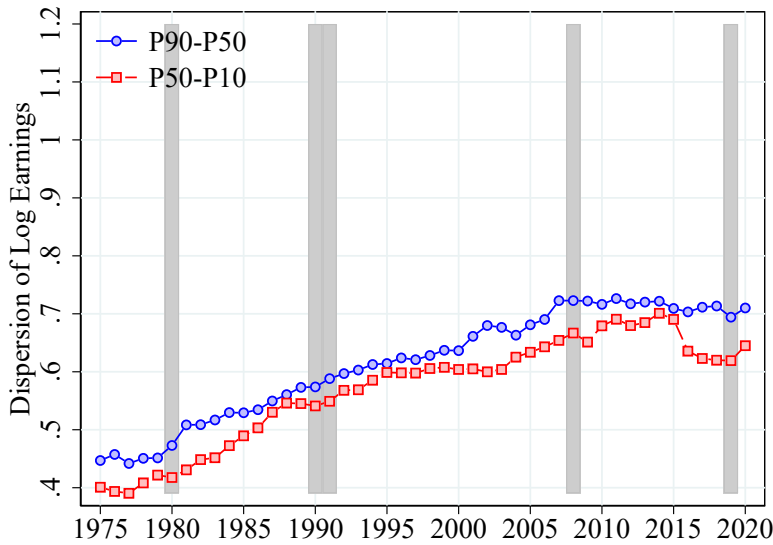

(c) Male

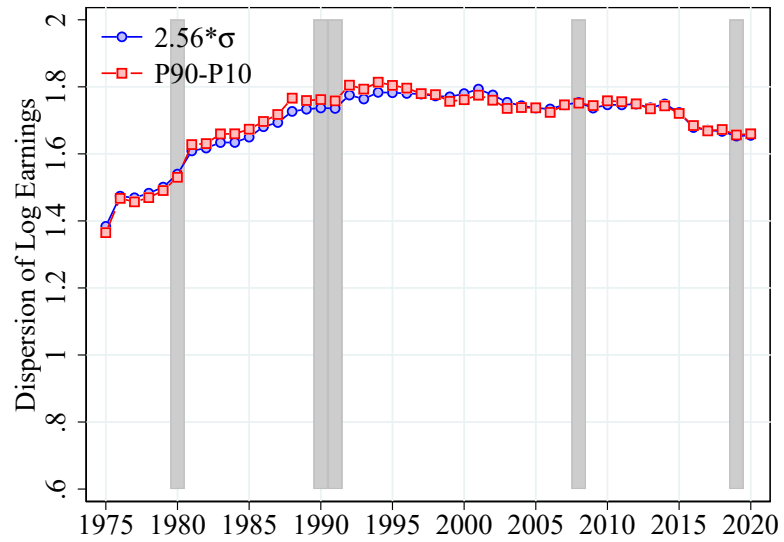

(b) Female

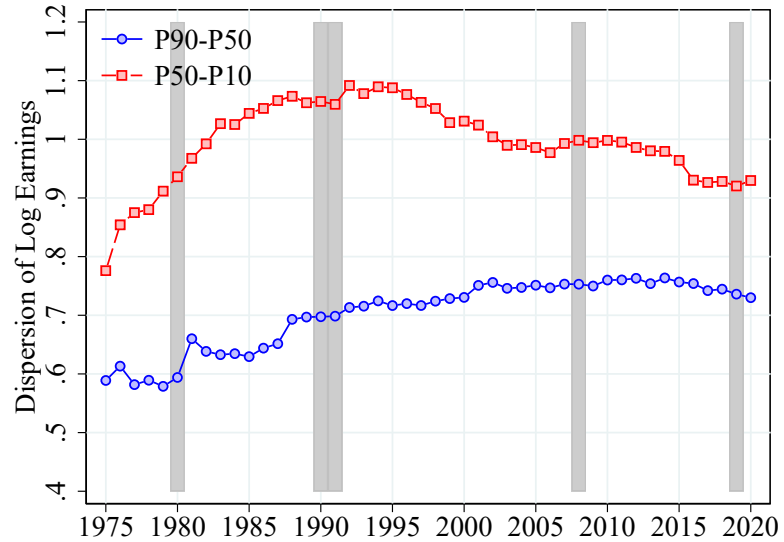

(d) Female

Notes: Raw log earnings and CS sample. Shaded areas are recessions. $2.56 * \sigma$ corresponds to P90-10 differential for a Gaussian distribution.

Source: ASHE

In both the female and male wage distributions, it is possible to see the strong 1-year increase in the 10th percentile, and a substantial drop in P50-P10 for this year. The rising minimum wage coupled with low aggregate real wage growth has led to a decline in the dispersion of earnings.

Considering the period as a whole, there have been many explanations offered for the rise of wage inequality. Increasing education premiums account for some of the gap, with the wage gaps between graduates and non-graduates rising particularly fast throughout the 1980s and 1990s. A key factor underpinning rising inequality has been a relative increase in the demand for skilled workers. Labor market polarization (Goos and Manning, 2007) is also part of the story, with the share of jobs with the lowest and highest average occupational pay growing the fastest. Various studies of skill-biased technical change (Berman, Bound, and Machin, 1998; Machin and Van 
Reenen, 1998) have found support for technology being an important part of the story of rising wage inequality in the UK.

Figure 4: Income inequality aged 25

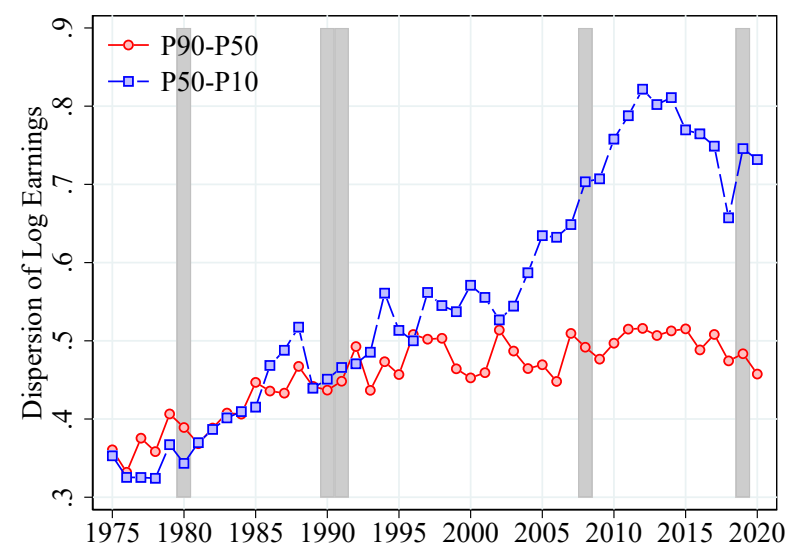

(a) Male

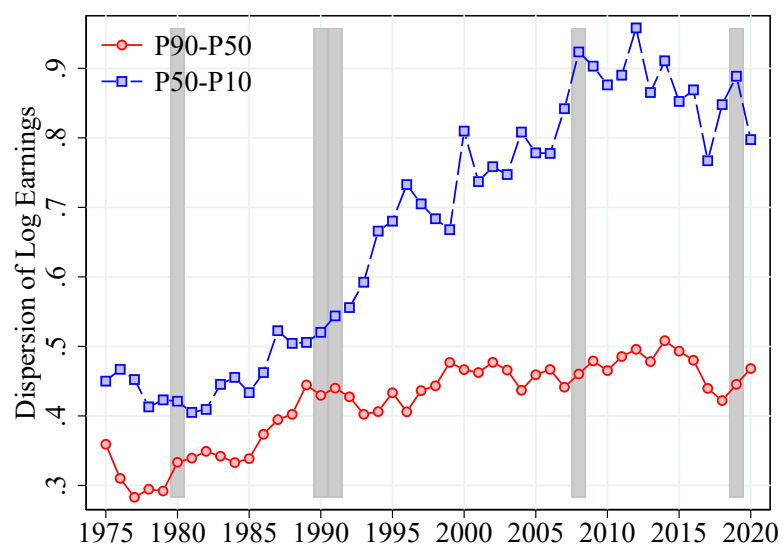

(b) Female

Notes: Raw log earnings and CS sample aged 25. Shaded areas are recessions.

Source: ASHE

Figure 5: Life-cycle inequality over cohorts

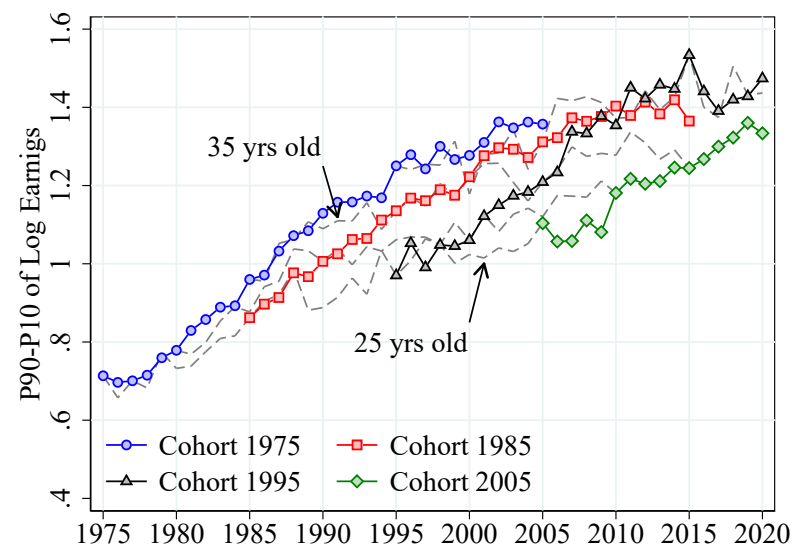

(a) Male

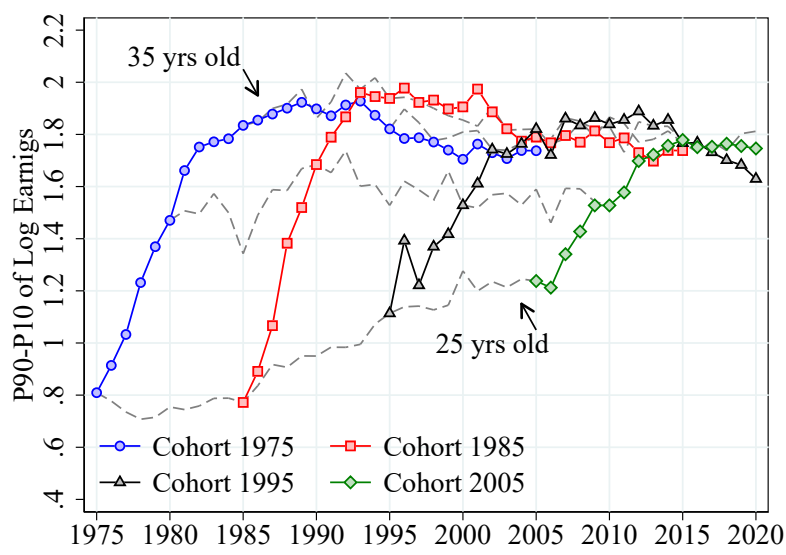

(b) Female

Notes: Raw log earnings and CS sample. Grey dashed lines correspond to earnings of 25, 30, 35 and 40 year olds as indicated by arrows. Each colored line corresponds to an individual cohort, where "cohort X" represents the cohort aged 25 in year X.

Source: ASHE

Figure 4 shows inequality for those aged 25 , close to the start of a workers' career. ${ }^{14}$ In panel (a), we see that male bottom-tail inequality has been rising throughout most of the period, partic-

\footnotetext{
${ }^{14}$ In the UK, it is unusual to remain in tertiary education past the age of 25 .
} 
ularly since the early 2000s. Top-tail inequality has been relatively stable. The picture is broadly similar for female workers aged 25, though the sharp increase in bottom-tail inequality began earlier. There is a marked difference between the aggregate inequality patterns shown previously and those seen among the youngest workers.

In Figure 5 we show how earnings inequality progresses over the life cycle for different cohorts. The 1975 cohort here refers to workers aged 25 in 1975, so those born in 1950. The blue line shows earnings inequality among these workers throughout their working lives. The red line shows the same for the cohort born 10 years later. The gray dashed lines show earnings for individuals of $25,30,35$ and 40 years of age over time, as indicated by the arrow markers. For men, we see that inequality is increasing at a steady and relatively constant rate within cohort as each cohort ages. Comparing the two figures, we see that dispersion changes over the lifecycle more for women (panel (b)) than for men (panel (a)). Women see a large increase in dispersion between ages 25 and 35. For women, all the increase in dispersion comes in the first decade of labor market experience, unlike among men for whom dispersion increases over the lifecycle.

\subsection{Volatility}

Similar to what has been found in the US, studies of income and earnings volatility in the UK have found a variety of results which are not always consistent with one-another, and vary by dataset and methodology. Most of the existing work on income dynamics in the UK has used survey data, and is best reviewed in Jenkins (2011a). The BHPS has been used in Jenkins (2011b) and Cappellari and Jenkins (2014), the latter of which uses non-parametric measures similar to those of this paper, finding a slight decline in earnings volatility. Francesco Devicienti (2011) fits several variance component model specifications to BHPS data and finds little change over time. Ramos (2003) on the other hand uses the same data to show an increase in the transitory component of earnings from 1991-1999. Dickens (2000) finds an increase in the transitory variance of earnings using the New Earnings Survey from 1985-1995. Dickens and McKnight (2008) using the Lifetime Labor Markets Database (LLMDB) find falling mobility for men. Kalwij and Alessie (2007) use NES data to show increases in both the transitory and permanent component of wages between 1975 and 2001.

We contribute to this literature by examining a longer time period, and using non-parametric methods which are increasingly recognized for their robustness and rely on few assumptions of underlying earnings processes, but which require a large amount of data. We present various statistics on workers' earnings changes over 1-year and 5-year periods. These figures show that consistent with the US evidence in Guvenen, Karahan, et al. (2015) earnings changes are leptokurtic, exhibiting substantial deviations from the log normal distribution. In terms of skewness, for one- 
year earnings changes we find a relatively symmetric distribution. For five-year changes we find negative skewness, in line with the recent US evidence. 15

Figure 6: Dispersion of 1-year log earnings changes

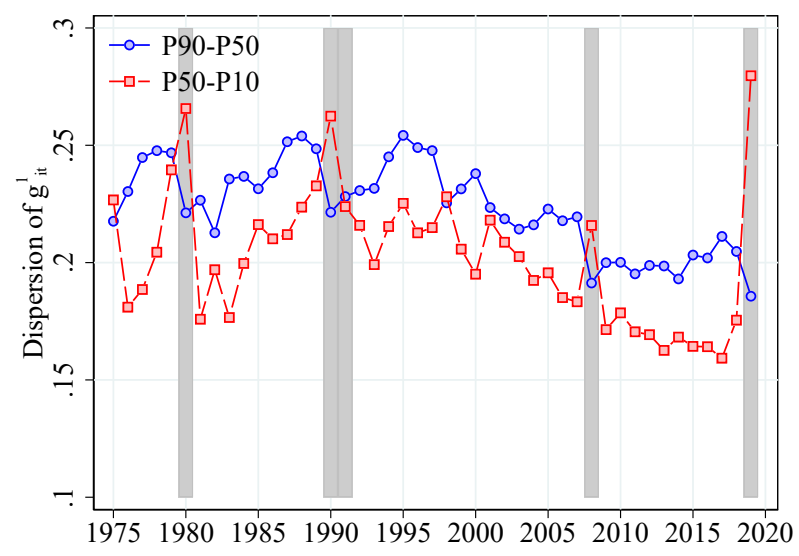

(a) Male

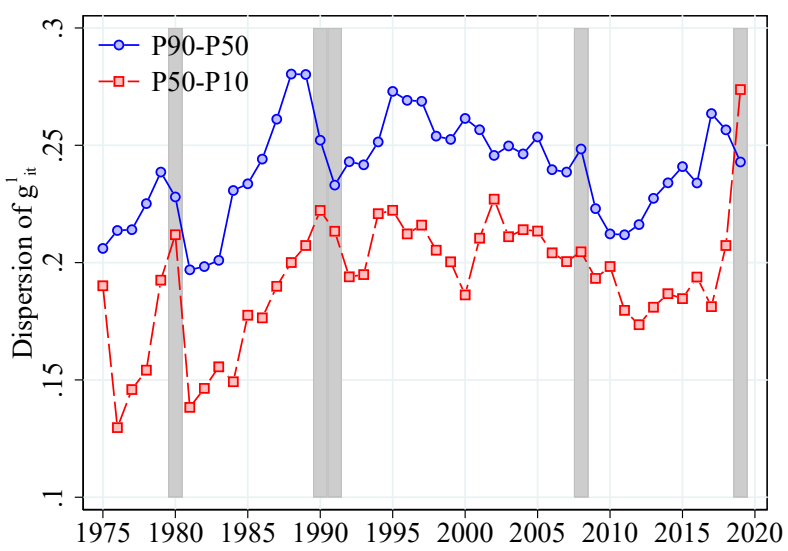

(b) Female

Notes: Residual one-year earnings changes and LX sample. Shared areas are recessions.

Source: ASHE

In Figure 6 we show top and bottom tail dispersion in 1-year log earnings changes. In panel (a), we see spikes in P50-P10 and drops in P90-P50 around recessions for men. The spike in the most recent recession (2020) stands out as an outlier. The most recent recession dwarfs the previous three in terms of its effect on lower-tail wage volatility. For both men and women, the P50-P10 statistic is higher in 2020 than in any previous period. As will be discussed later in this article, this likely stems from large wage cuts associated with being furloughed during the COVID-19 shock.

In terms of aggregate volatility, as measured by the sum of P90-P50 and P50-P10, for men there appears to have been a decline in volatility from the mid-1990s onwards, with fewer workers seeing large wage changes relative to the median. As in the US, this was a period of macroeconomic stability in the UK, and the patterns here match those in Sabelhaus and Song (2010). The trend is less clear for women.

Figure 7 shows non-parametric measures of skewness and kurtosis of one-year earnings changes over time. ${ }^{16}$ Reflecting the patterns discussed in the previous figure, skewness is strongly procyclical, dropping in recessions. The pattern is more visible for men than for women, reflecting a greater sensitivity to business cycle fluctuations among male workers. This figure also again shows

\footnotetext{
${ }^{15}$ The lack of any skewness in one-year changes may reflect the under-sampling of movers in the ASHE dataset. Where possible we present both 1 and 5 year earnings changes.

${ }^{16}$ These measures are as follows. Kelley Skewness is $\frac{(P 90-P 50)-(P 50-P 10)}{(P 90-P 10)}$. Excess Crow-Siddiqui kurtosis calculated as $\frac{P 97.5-P 2.5}{P 75-P 25}-2.91$, where the first term is Crow-Siddiqui kurtosis and the second is the value of this measure for the normal distribution.
} 
Figure 7: Skewness and kurtosis of 1-year log earnings changes

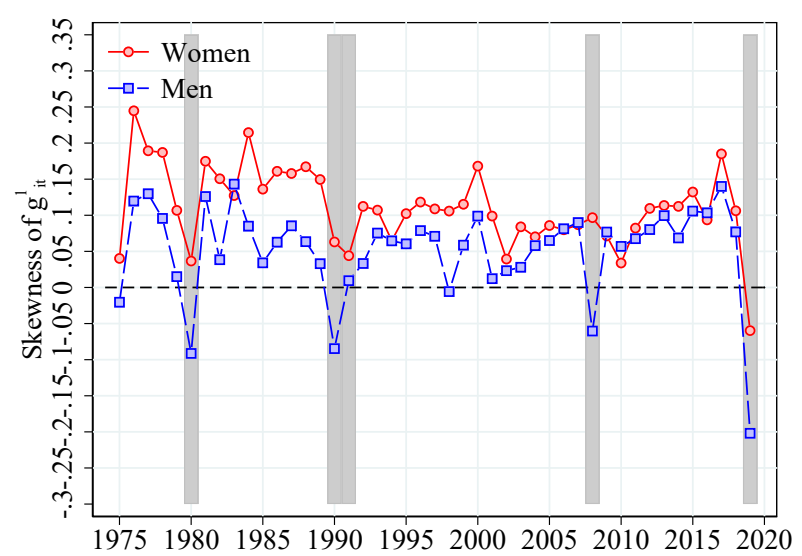

(a) Skewness

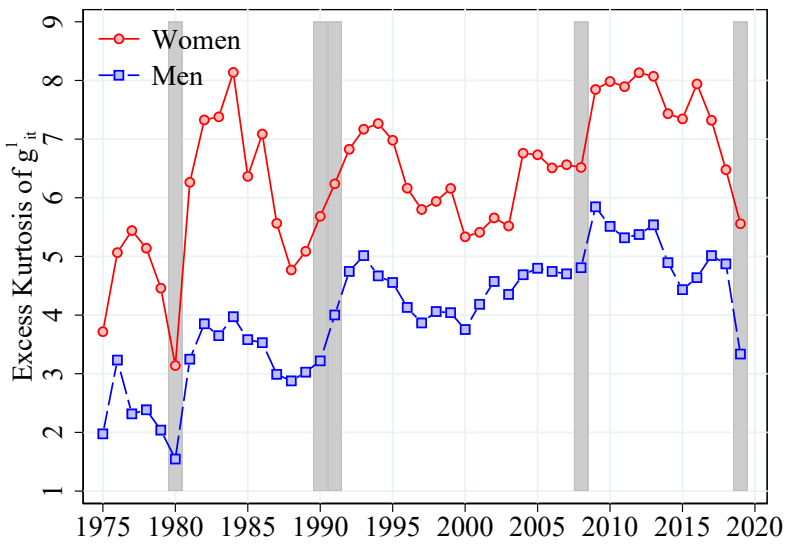

(b) Kurtosis

Notes: Residual one-year earnings changes and LX sample. Shared areas are recessions. Kelley skewness is $\frac{(P 90-P 50)-(P 50-P 10)}{(P 90-P 10)}$. Excess Crow-Siddiqui kurtosis calculated as $\frac{P 97.5-P 2.5}{P 75-P 25}-2.91$, where the first term is Crow-Siddiqui kurtosis and the second is the value of this measure for the normal distribution.

Source: ASHE

the scale of the 2020 shock, with male and female earnings changes reaching their lowest skewness of any year across the 45-year period. There does not seem to be any aggregate trend in skewness, and for most periods earnings changes exhibit a mild positive skew.

\subsection{Mobility}

In this section we present patterns of wage mobility. Whereas the previous section of volatility, focused on absolute wage changes, here we look at how individual workers' positions in the income distribution evolves over time.

Figure 8 shows 10 -year mobility for two different age groups. The lines give the mean percentile of workers in the $t+10$ permanent income distribution for workers at different points in the permanent income distribution at year $t$. Permanent income is defined as in the data section above. The dashed diagonal black line corresponds to perfect immobility. For both men and women, we see that stickiness is greater at the top of the distribution than the bottom, which the curve lines becoming steep in the top few percentiles. Mobility is declining in age for both genders. As workers age, their position in the income distribution becomes stickier.

Figure 9 shows how 10-year mobility has evolved over time. For men, we see a decline in mobility from 1977 through 1990 to 2015 . To the left of the intersection with the 45 degree line, the line for the first year is above those for the later years. To the right of the intersection, it lies below them. Stickiness at the top increased from 1977 to 1990, before falling back somewhat in 2005. 
Figure 8: Evolution of 10-year mobility over the life cycle

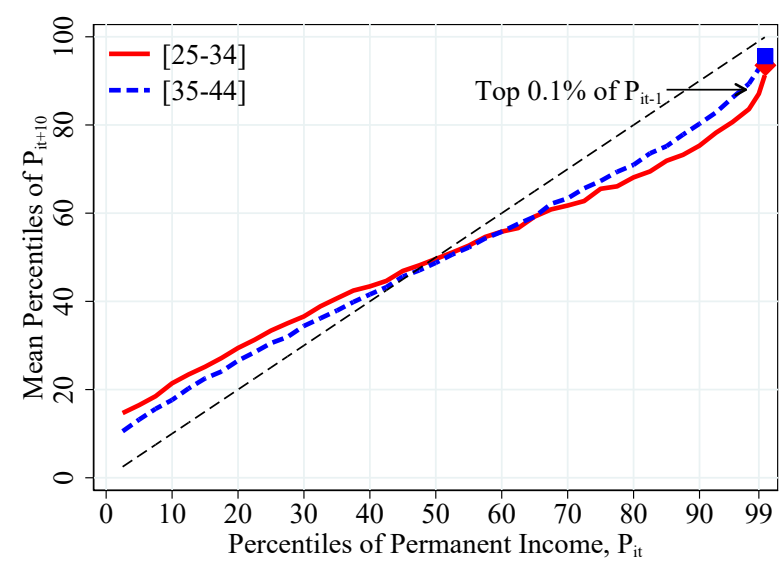

(a) Male

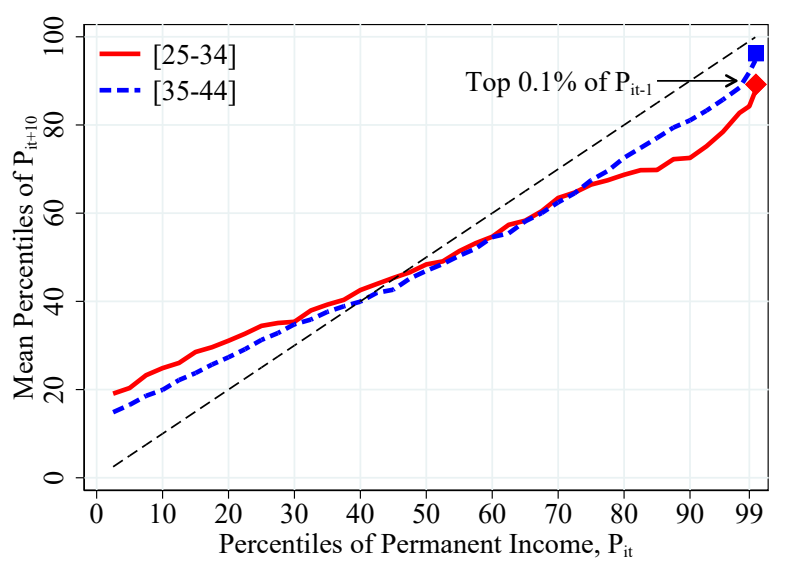

(b) Female

Notes: Permanent income and sample containing all those with permanent income at $t$ and $t+10$. Permanent income calculated using earnings from $t, t-1$ and $t-2$ as described in the text. Workers placed into 41 bins on $\mathrm{x}$ axis, where top bin refers to top $0.1 \%$ of earners and all other bins correspond to evenly-spaced quantiles.

Source: ASHE

\section{Figure 9: Evolution of 10-year mobility over time}

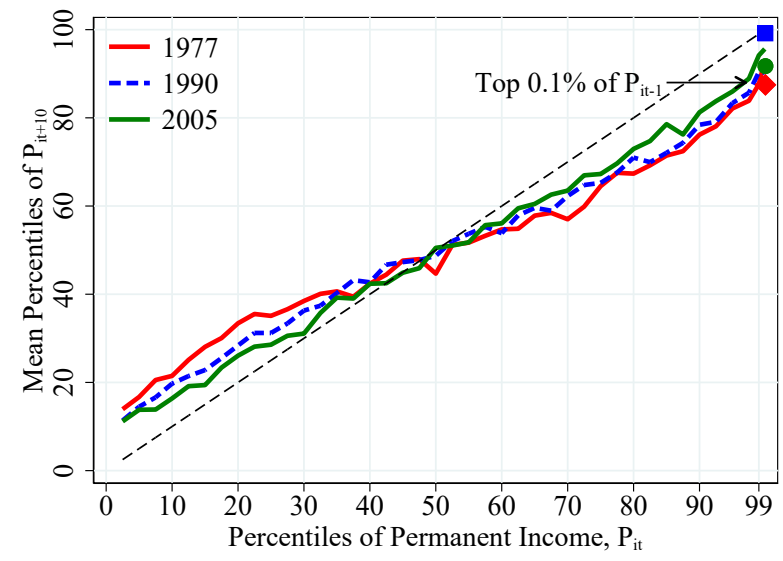

(a) Male

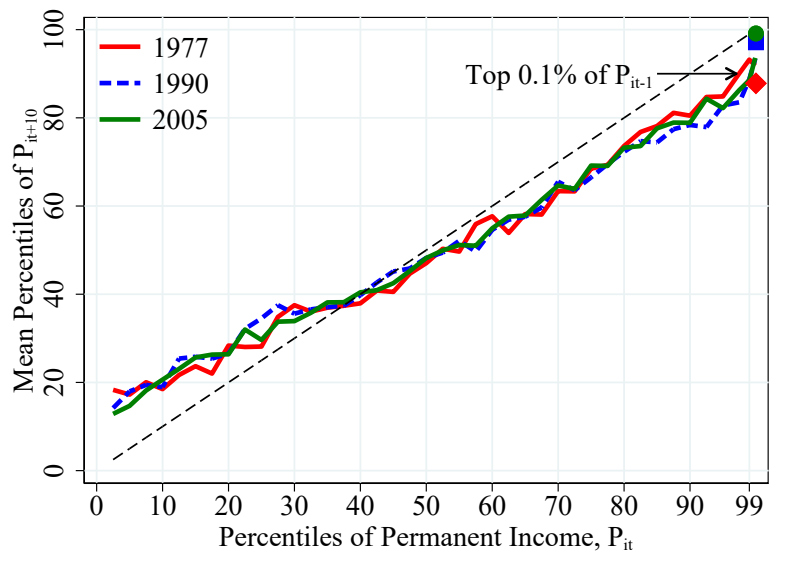

(b) Female

Notes: Permanent income and sample containing all those with permanent income at $t$ and $t+10$. Permanent income calculated using earnings from $t, t-1$ and $t-2$ as described in the text. Workers placed into 41 bins on $\mathrm{x}$ axis, where top bin refers to top $0.1 \%$ of earners and all other bins correspond to evenly-spaced quantiles.

Source: ASHE

This is consistent with Dickens and McKnight (2008), who find that male earnings mobility fell throughout the 1980s and 1990s. For women, there is little change across most of the distribution, though 10-year stickiness has increased towards the top of the distribution. 


\section{Wage and hours responses to aggregate and firm-level shocks}

In this section we exploit the long time dimension of our dataset and the availability of information on hours, to explore how aggregate and firm-level shocks affect workers' wages and hours. We also exploit the recent availability of data for 2020 to examine the impact of the COVID recession and compare it with previous recessions.

\subsection{Aggregate shocks}

Here we estimate how workers' wages and hours respond to changes in real GDP. This relates to a recent literature using administrative data (Guvenen, Schulhofer-Wohl, et al., 2017) and an older literature on wage cyclicality (Devereux and Hart, 2006). In column (1) of Table 2 we report the estimated elasticity of (weekly) earnings with respect to GDP, obtained by regressing changes in log weekly earnings on changes in log real GDP. The estimate, which we will refer to as 'GDP beta', is 0.381 , meaning that a $1 \%$ increase in real GDP is associated with an increase of roughly $0.4 \%$ in real weekly earnings. ${ }^{17}$ In column (2), we include an indicator for whether or not the economy is in recession, defined by a period of negative real GDP growth, whilst in column (3) we allow for asymmetries in the elasticity, interacting the recession indicator with GDP growth. Columns (2) and (3) make it clear that there are strong asymmetries. Column (3) shows that in non-recession years, the elasticity is 0.73 , almost double the aggregate number from column (1). Out of the 45 years for which we construct earnings changes, only 5 are recessions. These 5 years have a strong impact on the overall GDP beta. This suggests that estimates of GDP beta require long time dimensions to be estimated robustly. With short panels, the estimated coefficient will strongly depend on the number of recession years in the sample. The negative coefficient on the recession interaction in column (3) demonstrates that workers are protected from large earnings declines during recessions, consistent with previous UK evidence in Gregg, Machin, and Fernández-Salgado (2014).

\footnotetext{
${ }^{17}$ We have performed an exercise in which we compare the GDP response of annual earnings to that of weekly earnings. For the overlapping years, the estimates approximately coincide.
} 
Table 2: GDP beta estimates

\begin{tabular}{lcccccc}
\hline & \multicolumn{3}{c}{ Earnings } & & \multicolumn{3}{c}{ Hours } \\
& $(1)$ & $(2)$ & $(3)$ & $(4)$ & $(5)$ & $(6)$ \\
\hline$\Delta \mathrm{GDP}$ & $0.381^{* * *}$ & $0.552^{* * *}$ & $0.730^{* * *}$ & $0.155^{* * *}$ & $0.046^{* * *}$ & $0.050^{* * *}$ \\
& $(0.01)$ & $(0.01)$ & $(0.01)$ & $(0.00)$ & $(0.01)$ & $(0.01)$ \\
Recession & & $0.015^{* * *}$ & $0.007^{* * *}$ & & $-0.009^{* * *}$ & $-0.010^{* * *}$ \\
& & $(0.00)$ & $(0.00)$ & & $(0.00)$ & $(0.00)$ \\
$\Delta$ GDP $\times$ Recession & & & $-0.680^{* * *}$ & & & -0.017 \\
& & & $(0.02)$ & & & $(0.02)$ \\
Constant & $0.029^{* * *}$ & $0.024^{* * *}$ & $0.019^{* * *}$ & $0.001^{* * *}$ & $0.004^{* * *}$ & $0.004^{* * *}$ \\
& $(0.00)$ & $(0.00)$ & $(0.00)$ & $(0.00)$ & $(0.00)$ & $(0.00)$ \\
\hline Dep var mean & 0.037 & 0.037 & 0.037 & 0.004 & 0.004 & 0.004 \\
R-squared & 0.001 & 0.001 & 0.001 & 0.000 & 0.000 & 0.000 \\
$\mathrm{~N}$ & $4,575,704$ & $4,575,704$ & $4,575,704$ & $4,575,704$ & $4,575,704$ & $4,575,704$ \\
\hline
\end{tabular}

Notes: $* \mathrm{p}<0.1, * * \mathrm{p}<0.05, * * * \mathrm{p}<0.01$. Dependent variable in columns (1)-(3) is change in real log hourly earnings and in columns (4)-(6) is change in log hours worked. Standard errors clustered by worker. Years 1975-2020.

Source: ASHE

In columns (4), (5) and (6) we repeat the exercise for changes in log hours of work. From column (4), we can see that hours responses are relatively large. The coefficient of 0.155 is around two-fifths of the coefficient in column (1), suggesting that a significant share of the response of weekly earnings to aggregate fluctuations can be explained by changes in hours worked. Given the discussion of our hours variable in the data section, if anything this is likely to be an underestimate of the importance of hours.

Columns (5) and (6) again show strong asymmetries. In non-recession years, the coefficient falls below 0.05. Comparing the first row of column (6) to that of column (3) suggests that in nonrecession years, a small share of the weekly earnings response can be explained by hours changes. The high coefficient in column (4) can be explained by strong declines in hours of work in recession years.

The results of Table 2 are consistent with the large body of work on wage rigidities. In recessions, as hourly wages cannot be reduced sufficiently, to reduce labor costs firms reduce hours of work. In times of economic growth, hours are relatively unresponsive to differences in growth rates. Instead, adjustment comes through hourly wages.

Next we explore how the estimated GDP beta varies across worker characteristics, asking whether workers bear the incidence of aggregate shocks equally. We find patterns that closely match those for the US presented in Guvenen, Schulhofer-Wohl, et al. (2017).

In Table 3 column (1) we interact the change in GDP with gender. We see that women's earnings are less responsive to aggregate shocks, with an estimated elasticity of 0.28 relative to an estimate of 0.47 for men. In column (2) we interact with a set of age group dummies. Responsiveness is highest 
for the youngest workers (the omitted group), decreasing with age for most of the distribution before rising again for the oldest workers. In column (3) we include an indicator for public sector and an indicator for unionization. As the two are highly correlated, unlike in the other columns we include both predictors in the same regression. We see that both have a dampening effect on the estimated relationship. Those in the public sector experience half the aggregate earnings risk of those in the private sector.

Next in column (4) we include firm size dummies. Responsiveness to aggregate shocks is highest for workers with the smallest employers (the omitted group). Those working for employers with 2000 or more employees have an estimated GDP beta which is a quarter of that of those at employers with under 100 employees. In column (5) we estimate heterogeneity by skill level. The earnings of those in higher skilled occupations are less responsive to GDP. Those in high skilled occupation bear around a third of the aggregate earnings risk as those in low skilled occupations. ${ }^{18}$ Finally in column (6) we report heterogeneity estimates by quantile of the wage distribution (an alternative skill measure), which again points to reduced exposure to aggregate fluctuations for the most skilled.

In Table 4 we perform the same exercise with hours as the outcome variable. In column (1), we can see that as was the case with earnings, women's hours are less responsive to aggregate shocks. When it comes to age, the patterns are different. The hours of the youngest workers are actually the least responsive to aggregate shocks. Older workers, and particularly those aged over 55, see the most responsiveness of hours to aggregate shocks. In column (3), we see that as with earnings, public sector workers are shielded from changes in hours. However, union-covered workers' hours are more responsive to aggregate shocks. This makes sense if one considers that wage rigidities are particularly binding for this group, so hours adjustments become more attractive for employers faced with shocks. For firm size in column (4), we see the same patterns as when the outcome variable was weekly earnings, with those at larger employers seeing a lower responsiveness. In column (5), we see that low skilled workers are the most responsive in terms of hours. As the sample for the final result includes only the COVID-19 recession, we again stress caution when interpreting these estimates. Due to the furlough scheme, discussed further below, hours data from 2020 are likely to be less reliable than for other years.

\footnotetext{
${ }^{18}$ For this column, we are only able to use data from 2011 onwards, so these estimates will to a significant extent be driven by the most recent COVID-19 recession.
} 
Table 3: Log earnings GDP beta heterogeneity

\begin{tabular}{|c|c|c|c|c|c|c|}
\hline & (1) & (2) & (3) & (4) & (5) & (6) \\
\hline$\Delta \mathrm{GDP}$ & $\begin{array}{c}0.470^{* * *} \\
(0.01)\end{array}$ & $\begin{array}{c}0.450^{* * *} \\
(0.02)\end{array}$ & $\begin{array}{c}0.541^{* * *} \\
(0.01)\end{array}$ & $\begin{array}{c}0.720^{* * *} \\
(0.02)\end{array}$ & $\begin{array}{c}1.008^{* * *} \\
(0.04)\end{array}$ & $\begin{array}{c}0.398^{* * *} \\
(0.02)\end{array}$ \\
\hline$\Delta \mathrm{GDP} \times$ Female & $\begin{array}{c}-0.189^{* * *} \\
(0.01)\end{array}$ & & & & & \\
\hline \multicolumn{7}{|l|}{ Age: } \\
\hline $25-34 \times \Delta \mathrm{GDP}$ & & $\begin{array}{c}-0.084^{* * *} \\
(0.03)\end{array}$ & & & & \\
\hline $35-44 \times \Delta \mathrm{GDP}$ & & $\begin{array}{c}-0.077^{* * *} \\
(0.03)\end{array}$ & & & & \\
\hline $45-54 \times \Delta \mathrm{GDP}$ & & $\begin{array}{c}-0.167^{* * *} \\
(0.03)\end{array}$ & & & & \\
\hline $55-64 \times \Delta \mathrm{GDP}$ & & $\begin{array}{c}-0.060^{* *} \\
(0.03)\end{array}$ & & & & \\
\hline$\Delta$ GDP $\times$ Public & & & $\begin{array}{c}-0.278^{* * *} \\
(0.01)\end{array}$ & & & \\
\hline$\Delta \mathrm{GDP} \times$ Union & & & $\begin{array}{c}-0.184^{* * *} \\
(0.01)\end{array}$ & & & \\
\hline \multicolumn{7}{|l|}{ Firm size: } \\
\hline $100-499 \times \Delta \mathrm{GDP}$ & & & & $\begin{array}{c}-0.175^{* * *} \\
(0.03)\end{array}$ & & \\
\hline $500-1999 \times \Delta \mathrm{GDP}$ & & & & $\begin{array}{c}-0.370^{* * *} \\
(0.03)\end{array}$ & & \\
\hline $2000+\times \Delta \mathrm{GDP}$ & & & & $\begin{array}{c}-0.566^{* * *} \\
(0.02)\end{array}$ & & \\
\hline \multicolumn{7}{|l|}{ Skill: } \\
\hline Mid $\times \Delta$ GDP & & & & & $\begin{array}{l}-0.423^{* * *} \\
(0.05)\end{array}$ & \\
\hline High $\times \Delta$ GDP & & & & & $\begin{array}{c}-0.642^{* * *} \\
(0.05)\end{array}$ & \\
\hline \multicolumn{7}{|l|}{ Earnings: } \\
\hline $\mathrm{Q} 2 \times \Delta \mathrm{GDP}$ & & & & & & $\begin{array}{c}0.070^{* * *} \\
(0.02)\end{array}$ \\
\hline $\mathrm{Q} 3 \times \Delta \mathrm{GDP}$ & & & & & & $\begin{array}{c}0.055^{* * *} \\
(0.02)\end{array}$ \\
\hline $\mathrm{Q} 4 \times \Delta \mathrm{GDP}$ & & & & & & $\begin{array}{l}0.007 \\
(0.02)\end{array}$ \\
\hline $\mathrm{Q} 5 \times \Delta \mathrm{GDP}$ & & & & & & $\begin{array}{c}-0.072^{* * *} \\
(0.02)\end{array}$ \\
\hline Dep var mean & 0.037 & 0.037 & 0.037 & 0.037 & 0.037 & 0.037 \\
\hline $\mathrm{N}$ & $4,575,704$ & $4,575,704$ & $4,575,704$ & $2,555,948$ & 995,963 & $3,269,512$ \\
\hline
\end{tabular}

Notes: $* \mathrm{p}<0.1, * * \mathrm{p}<0.05, * * * \mathrm{p}<0.01$. Dependent variable is change in real log hourly earnings. Sample held fixed for columns (1) - (3). Sample is lower in columns (4)-(6) due to missing variables. Standard errors clustered by worker. Years 1975-2020.

Source: ASHE 
Table 4: Log hours GDP beta heterogeneity

\begin{tabular}{|c|c|c|c|c|c|c|}
\hline & (1) & (2) & (3) & (4) & (5) & (6) \\
\hline$\Delta \mathrm{GDP}$ & $\begin{array}{c}0.189^{* * *} \\
(0.01)\end{array}$ & $\begin{array}{c}0.056^{* * *} \\
(0.02)\end{array}$ & $\begin{array}{c}0.154^{* * *} \\
(0.01)\end{array}$ & $\begin{array}{c}0.161^{* * *} \\
(0.02)\end{array}$ & $\begin{array}{c}0.618^{* * *} \\
(0.04)\end{array}$ & $\begin{array}{c}0.153^{* * *} \\
(0.01)\end{array}$ \\
\hline$\Delta \mathrm{GDP} \times$ Female & $\begin{array}{c}-0.068^{* * *} \\
(0.01)\end{array}$ & & & & & \\
\hline \multicolumn{7}{|l|}{ Age: } \\
\hline $25-34 \times \Delta \mathrm{GDP}$ & & $\begin{array}{c}0.073^{* * *} \\
(0.02)\end{array}$ & & & & \\
\hline $35-44 \times \Delta \mathrm{GDP}$ & & $\begin{array}{c}0.112^{* * *} \\
(0.02)\end{array}$ & & & & \\
\hline $45-54 \times \Delta \mathrm{GDP}$ & & $\begin{array}{c}0.083^{* * *} \\
(0.02)\end{array}$ & & & & \\
\hline $55-64 \times \Delta \mathrm{GDP}$ & & $\begin{array}{c}0.164^{* * *} \\
(0.02)\end{array}$ & & & & \\
\hline$\Delta \mathrm{GDP} \times$ Public & & & $\begin{array}{c}-0.057^{* * *} \\
(0.01)\end{array}$ & & & \\
\hline$\Delta \mathrm{GDP} \times$ Union & & & $\begin{array}{c}0.055^{* * *} \\
(0.01)\end{array}$ & & & \\
\hline \multicolumn{7}{|l|}{ Firm size: } \\
\hline $100-499 \times \Delta \mathrm{GDP}$ & & & & $\begin{array}{l}0.008 \\
(0.02)\end{array}$ & & \\
\hline $500-1999 \times \Delta \mathrm{GDP}$ & & & & $\begin{array}{c}-0.054^{* *} \\
(0.02)\end{array}$ & & \\
\hline $2000+\times \Delta \mathrm{GDP}$ & & & & $\begin{array}{c}-0.077^{* * *} \\
(0.02)\end{array}$ & & \\
\hline \multicolumn{7}{|l|}{ Skill: } \\
\hline Mid $\times \Delta$ GDP & & & & & $\begin{array}{c}-0.412^{* * *} \\
(0.05)\end{array}$ & \\
\hline High $\times \Delta$ GDP & & & & & $\begin{array}{c}-0.428^{* * *} \\
(0.05)\end{array}$ & \\
\hline \multicolumn{7}{|l|}{ Earnings: } \\
\hline $\mathrm{Q} 2 \times \Delta \mathrm{GDP}$ & & & & & & $\begin{array}{l}0.027 \\
(0.02)\end{array}$ \\
\hline $\mathrm{Q} 3 \times \Delta \mathrm{GDP}$ & & & & & & $\begin{array}{l}0.015 \\
(0.02)\end{array}$ \\
\hline $\mathrm{Q} 4 \times \Delta \mathrm{GDP}$ & & & & & & $\begin{array}{l}0.001 \\
(0.02)\end{array}$ \\
\hline $\mathrm{Q} 5 \times \Delta \mathrm{GDP}$ & & & & & & $\begin{array}{c}-0.031^{*} \\
(0.02)\end{array}$ \\
\hline Dep var mean & 0.004 & 0.004 & 0.004 & 0.004 & 0.004 & 0.004 \\
\hline $\mathrm{N}$ & $4,575,704$ & $4,575,704$ & $4,575,704$ & $2,555,948$ & 995,963 & $3,269,512$ \\
\hline
\end{tabular}

Notes: $* \mathrm{p}<0.1, * * \mathrm{p}<0.05, * * * \mathrm{p}<0.01$. Dependent variable is change in log hours worked. Sample held fixed for columns (1) - (3). Sample is lower in columns (4)-(6) due to missing variables. Standard errors clustered by worker. Years 1975-2020.

Source: ASHE 


\subsection{The 2020 recession}

The data used for the UK are uniquely up-to-date. This enables us to investigate patterns in the most recent recession. As shown in Section 3 of this paper, the COVID-19 shock has resulted in substantial wage drops for many workers. Here we investigate this in more detail, focusing on the size of the falls relative to previous recessions and on the role of the UK's furlough policy. ${ }^{19}$

In Table 5 we inspect heterogeneity in earnings changes from April 2019 to April 2020, comparing this year to the previous 9 years of April to April wage changes. We see that qualitatively, the earnings patterns of this recession appear similar to those of the average recession from the previous section. To more directly compare the response of earnings in the COVID-19 recession to those of previous shocks, in Figure 1 we plot the patterns predicted from the estimates reported in Table 3 for a drop in GDP of $7.4 \%$. This is the annual change in the monthly GDP index as of March 2020 - the month just prior to the earnings data being reported. It is also close to the overall fall in GDP for 2020, which was 9.9\%. These are given in the "Predicted COVID-19 effect" bars. ${ }^{20}$ We then compare these with the figures reported in Table 5, indicated in the figure as "Actual COVID-19 effect". Despite the very different causes of the COVID-19 recession, in terms of earnings the relative size of the effects are very close to what would have been predicted given the size of the GDP shock and the historic beta estimates. Across all workers, the predicted effect on earnings is $2.8 \%$, which is a little greater than the actual estimated effect of $2.3 \% .^{21}$ This broad similarity of previous shocks and the COVID-19 shock in terms of labor market effects has also been shown in survey data by Bell, Codreanu, and Machin (2020).

As in previous recessions, younger workers are the most exposed to the COVID-19 shock in terms of earnings, followed by the very oldest workers. Higher earners are less exposed, with the COVID-19 recession seeing a steeper gradient across permanent earnings than that found in previous years. COVID-19 has hit those in smaller firms the hardest, in line with our expectations based on previous shocks. Despite the ample literature showing the shock to have a disproportionate effect on female workers (Adams-Prassl et al., 2020; Alon et al., 2020), we find that in terms of earnings, men experienced a larger shock. Our data are not well suited to studying the extensive margin, however Bell, Codreanu, and Machin (2020) find little gender difference in the employment effect of the COVID-19 recession. ${ }^{22}$ This suggests that including zero earnings would not change the result here that male earnings have taken a harder hit than female earnings.

As in previous recessions, those in the private sector and outside of union agreements have the

\footnotetext{
${ }^{19}$ The caveat to this section is that firm non-response for this year was higher than in previous years, meaning the sample is smaller. Non-response is not likely to be random, and a reasonable assumption is that firms who experienced a greater negative shock were less likely to respond.

${ }^{20}$ The qualitative patterns from Table 3 and Table 4 hold with the latest recession excluded.

${ }^{21}$ This is approximate, and based on the results in Table 5.

${ }^{22}$ This is unlike in previous recessions, where male workers experienced greater drops in employment.
} 
largest drops, with public sector unionized workers seeing wage increases relative to recent years. ${ }^{23}$ While the cause of the 2020 recession is unique, in terms of how it is affecting the earnings of different workers, the qualitative patterns closely resemble those of previous recessions.

On aggregate, $26 \%$ of workers are furloughed in our data in April 2020. This aligns well with the ONS statistic of $27 \%$ for the same period across the UK workforce, derived from other sources. ${ }^{24}$ The scheme was open to all employers, and enabled employers to furlough employees in exchange for a cash grant of $80 \%$ of wages, up to GBP2,500 per month. The equivalent annual salary of 2,500 per month is close to the median annual salary in the UK in 2020. The employer can choose whether or not to top-up the remaining $20 \%$ of pay. While this changed later in the crisis, in April 2020 workers were not able to work any hours for their employer if they had been furloughed.

Firstly, we investigate the characteristics of workers who were likely to be furloughed. In Table 6 columns (1) and (2) we show estimates from a linear probability model in which the outcome variable is a binary indicator for whether a worker has been furloughed. In column (1) we can see that furlough is more likely for women, younger workers, private sector and non-unionized workers, those in smaller firms, low-skill workers and those with shorter firm tenures. These patterns are consistent with the survey evidence presented in Adams-Prassl et al. (2020).

Other than gender, we can see that the patterns here match those shown in the previous subsection. Those whose earnings tend to be more responsive to aggregate shocks are precisely those who were furloughed in the COVID-19 crisis. In column (2), we investigate how the probability of furlough varies by quintiles of permanent income, where permanent income is as defined above. We see a strong profile, with those at the bottom of the permanent income distribution significantly more likely to be furloughed.

In Appendix Table 13 we show the analogous estimates for hours, conditional on not being furloughed. The high prevalence of the furlough scheme makes these estimates difficult to interpret.

\footnotetext{
${ }^{23}$ These responses are calculated by summing the relevant coefficients. This pattern likely in part reflects public pay restraint since the Great Recession, meaning low increases in public pay in the early 2010s.

${ }^{24}$ ONS “Furloughing of workers across UK businesses: 23 March 2020 to 5 April 2020”, released 23 April 2020
} 
Table 5: Earnings changes in the 2020 recession

\begin{tabular}{|c|c|c|c|c|c|c|}
\hline & (1) & (2) & (3) & (4) & (5) & (6) \\
\hline 2020 & $\begin{array}{c}-0.036^{* * *} \\
(0.00)\end{array}$ & $\begin{array}{c}-0.036^{* * *} \\
(0.01)\end{array}$ & $\begin{array}{c}-0.038^{* * *} \\
(0.00)\end{array}$ & $\begin{array}{c}-0.058^{* * *} \\
(0.00)\end{array}$ & $\begin{array}{c}-0.036^{* * *} \\
(0.00)\end{array}$ & $\begin{array}{c}-0.024^{* * *} \\
(0.00)\end{array}$ \\
\hline $2020 \times$ Female & $\begin{array}{c}0.026^{* * *} \\
(0.00)\end{array}$ & & & & & \\
\hline \multicolumn{7}{|l|}{ Age: } \\
\hline $25-34 \times 2020$ & & $\begin{array}{c}0.015^{* *} \\
(0.01)\end{array}$ & & & & \\
\hline $35-44 \times 2020$ & & $\begin{array}{c}0.017^{* *} \\
(0.01)\end{array}$ & & & & \\
\hline $45-54 \times 2020$ & & $\begin{array}{c}0.016^{* *} \\
(0.01)\end{array}$ & & & & \\
\hline $55-64 \times 2020$ & & $\begin{array}{l}0.014^{*} \\
(0.01)\end{array}$ & & & & \\
\hline $2019 \times$ Public & & & $\begin{array}{c}0.029^{* * *} \\
(0.00)\end{array}$ & & & \\
\hline $2019 \times$ Union & & & $\begin{array}{c}0.026^{* * *} \\
(0.00)\end{array}$ & & & \\
\hline \multicolumn{7}{|l|}{ Firm size: } \\
\hline $100-499 \times 2020$ & & & & $\begin{array}{c}0.020^{* * *} \\
(0.00)\end{array}$ & & \\
\hline $500-1999 \times 2020$ & & & & $\begin{array}{c}0.036^{* * *} \\
(0.00)\end{array}$ & & \\
\hline $2000+\times 2020$ & & & & $\begin{array}{c}0.061^{* * *} \\
(0.00)\end{array}$ & & \\
\hline \multicolumn{7}{|l|}{ Skill: } \\
\hline Mid $\times 2020$ & & & & & $\begin{array}{c}0.014^{* * *} \\
(0.00)\end{array}$ & \\
\hline High $\times 2020$ & & & & & $\begin{array}{c}0.025^{* * *} \\
(0.00)\end{array}$ & \\
\hline \multicolumn{7}{|l|}{ Earnings: } \\
\hline $\mathrm{Q} 2 \times 2020$ & & & & & & $\begin{array}{l}-0.002 \\
(0.00)\end{array}$ \\
\hline $\mathrm{Q} 3 \times 2020$ & & & & & & $\begin{array}{l}-0.001 \\
(0.00)\end{array}$ \\
\hline $\mathrm{Q} 4 \times 2020$ & & & & & & $\begin{array}{c}0.009^{* *} \\
(0.00)\end{array}$ \\
\hline $\mathrm{Q} 5 \times 2020$ & & & & & & $\begin{array}{c}0.015^{* * *} \\
(0.00)\end{array}$ \\
\hline Dep var mean & 0.028 & 0.028 & 0.028 & 0.028 & 0.028 & 0.028 \\
\hline $\mathrm{N}$ & $1,120,506$ & $1,120,506$ & $1,120,506$ & $1,120,506$ & 995,963 & 820,837 \\
\hline
\end{tabular}

Notes: $* \mathrm{p}<0.1, * * \mathrm{p}<0.05, * * * \mathrm{p}<0.01$. Dependent variable is change in real log hourly earnings. Sample held fixed for columns (1) - (4). Sample is lower in columns (5)-(6) due to missing variables. Standard errors clustered by worker. Years 2010-2020.

Source: ASHE 
Table 6: Furlough and pay top-ups

\begin{tabular}{|c|c|c|c|c|}
\hline & \multicolumn{2}{|c|}{ Furlough } & \multicolumn{2}{|c|}{ Pay top-up } \\
\hline & (1) & (2) & (3) & (4) \\
\hline Female & $\begin{array}{c}0.018^{* * *} \\
(0.00)\end{array}$ & $\begin{array}{c}0.020^{* * *} \\
(0.00)\end{array}$ & $\begin{array}{l}0.001 \\
(0.01)\end{array}$ & $\begin{array}{l}0.005 \\
(0.01)\end{array}$ \\
\hline Age $25-34$ & $\begin{array}{c}-0.046^{* * *} \\
(0.00)\end{array}$ & $\begin{array}{c}-0.073^{* * *} \\
(0.01)\end{array}$ & $\begin{array}{l}0.009 \\
(0.01)\end{array}$ & $\begin{array}{c}0.073^{* * *} \\
(0.02)\end{array}$ \\
\hline Age $35-44$ & $\begin{array}{c}-0.061^{* * *} \\
(0.00)\end{array}$ & $\begin{array}{c}-0.094^{* * *} \\
(0.01)\end{array}$ & $\begin{array}{c}0.046^{* * *} \\
(0.01)\end{array}$ & $\begin{array}{c}0.106^{* * *} \\
(0.02)\end{array}$ \\
\hline Age $45-54$ & $\begin{array}{c}-0.074^{* * *} \\
(0.01)\end{array}$ & $\begin{array}{c}-0.103^{* * *} \\
(0.01)\end{array}$ & $\begin{array}{c}0.036^{* * *} \\
(0.01)\end{array}$ & $\begin{array}{c}0.098^{* * *} \\
(0.02)\end{array}$ \\
\hline Age 55-64 & $\begin{array}{c}-0.057^{* * *} \\
(0.01)\end{array}$ & $\begin{array}{c}-0.082^{* * *} \\
(0.01)\end{array}$ & $\begin{array}{c}0.029^{* * *} \\
(0.01)\end{array}$ & $\begin{array}{c}0.089^{* * *} \\
(0.02)\end{array}$ \\
\hline Public & $\begin{array}{c}-0.081^{* * *} \\
(0.00)\end{array}$ & $\begin{array}{c}-0.081^{* * *} \\
(0.01)\end{array}$ & $\begin{array}{c}0.252^{* * *} \\
(0.03)\end{array}$ & $\begin{array}{c}0.222^{* * *} \\
(0.03)\end{array}$ \\
\hline Union & $\begin{array}{c}-0.034^{* * *} \\
(0.00)\end{array}$ & $\begin{array}{c}-0.028^{* * *} \\
(0.00)\end{array}$ & $\begin{array}{c}-0.068^{* * *} \\
(0.02)\end{array}$ & $\begin{array}{c}-0.061^{* * *} \\
(0.02)\end{array}$ \\
\hline $100-499 \mathrm{emp}$ & $\begin{array}{c}-0.121^{* * *} \\
(0.00)\end{array}$ & $\begin{array}{c}-0.117^{* * *} \\
(0.00)\end{array}$ & $\begin{array}{c}-0.079^{* * *} \\
(0.01)\end{array}$ & $\begin{array}{c}-0.075^{* * *} \\
(0.01)\end{array}$ \\
\hline 500-1999 emp & $\begin{array}{c}-0.144^{* * *} \\
(0.00)\end{array}$ & $\begin{array}{c}-0.134^{* * *} \\
(0.00)\end{array}$ & $\begin{array}{c}-0.042^{* * *} \\
(0.01)\end{array}$ & $\begin{array}{c}-0.013 \\
(0.01)\end{array}$ \\
\hline $2000+\mathrm{emp}$ & $\begin{array}{c}-0.195^{* * *} \\
(0.00)\end{array}$ & $\begin{array}{c}-0.174^{* * *} \\
(0.00)\end{array}$ & $\begin{array}{c}0.087^{* * *} \\
(0.01)\end{array}$ & $\begin{array}{c}0.083^{* * *} \\
(0.01)\end{array}$ \\
\hline Mid skill & $\begin{array}{c}-0.020^{* * *} \\
(0.00)\end{array}$ & $\begin{array}{l}-0.000 \\
(0.00)\end{array}$ & $\begin{array}{c}0.041^{* * *} \\
(0.01)\end{array}$ & $\begin{array}{c}0.035^{\text {*** }} \\
(0.01)\end{array}$ \\
\hline High skill & $\begin{array}{c}-0.092^{* * *} \\
(0.00)\end{array}$ & $\begin{array}{c}-0.038^{* * *} \\
(0.00)\end{array}$ & $\begin{array}{c}0.111^{* * *} \\
(0.01)\end{array}$ & $\begin{array}{c}0.073^{\text {*** }} \\
(0.01)\end{array}$ \\
\hline $1-2$ years tenure & $\begin{array}{l}0.005 \\
(0.00)\end{array}$ & $\begin{array}{l}-0.006 \\
(0.01)\end{array}$ & $\begin{array}{l}0.009 \\
(0.01)\end{array}$ & $\begin{array}{l}0.003 \\
(0.01)\end{array}$ \\
\hline $3-4$ years tenure & $\begin{array}{l}-0.003 \\
(0.00)\end{array}$ & $\begin{array}{l}0.001 \\
(0.01)\end{array}$ & $\begin{array}{c}0.030^{* * *} \\
(0.01)\end{array}$ & $\begin{array}{c}0.035^{* *} \\
(0.01)\end{array}$ \\
\hline $5-9$ years tenure & $\begin{array}{c}-0.020^{* * *} \\
(0.00)\end{array}$ & $\begin{array}{c}-0.016^{* * *} \\
(0.01)\end{array}$ & $\begin{array}{l}0.025^{* *} \\
(0.01)\end{array}$ & $\begin{array}{l}0.021 \\
(0.01)\end{array}$ \\
\hline 10 years + tenure & $\begin{array}{c}-0.026^{* * *} \\
(0.00)\end{array}$ & $\begin{array}{c}-0.019^{* * *} \\
(0.01)\end{array}$ & $\begin{array}{l}0.024^{* *} \\
(0.01)\end{array}$ & $\begin{array}{l}0.018 \\
(0.01)\end{array}$ \\
\hline \multicolumn{5}{|l|}{ Earnings: } \\
\hline Q2 & & $\begin{array}{c}-0.011^{* * *} \\
(0.00)\end{array}$ & & $\begin{array}{c}-0.030^{* * *} \\
(0.01)\end{array}$ \\
\hline Q3 & & $\begin{array}{c}-0.041^{* * *} \\
(0.00)\end{array}$ & & $\begin{array}{l}0.008 \\
(0.01)\end{array}$ \\
\hline Q4 & & $\begin{array}{c}-0.070^{* * *} \\
(0.00)\end{array}$ & & $\begin{array}{c}0.029^{* *} \\
(0.01)\end{array}$ \\
\hline Q5 & & $\begin{array}{c}-0.110^{* * *} \\
(0.00)\end{array}$ & & $\begin{array}{c}0.063^{* * *} \\
(0.02)\end{array}$ \\
\hline $\begin{array}{c}\text { Dep var mean } \\
\mathrm{N}\end{array}$ & $\begin{array}{c}0.254 \\
110,346\end{array}$ & $\begin{array}{c}0.254 \\
74,985\end{array}$ & $\begin{array}{c}0.524 \\
28,044\end{array}$ & $\begin{array}{c}0.524 \\
17,044\end{array}$ \\
\hline
\end{tabular}

Notes: $* \mathrm{p}<0.1, * * \mathrm{p}<0.05, * * * \mathrm{p}<0.01$. Linear probability model with outcome variable $=1$ if worker is furloughed in columns (1)-(2) and outcome variable $=1$ if pay topped up by employer in columns (3)-(4). Year 2020.

Source: ASHE 
Our data also indicates whether employers have opted to top up furloughed workers' salaries to normal levels. This was asked directly, and has not been inferred from earnings data. In Table 6 columns (3) and (4) we repeat the specifications of columns (1) and (2) with an outcome variable which equals one if the worker's wages are topped up by their employer. ${ }^{25}$ These regressions $^{2}$ include only furloughed workers. On aggregate, approximately half of furloughed workers had their wages topped up by their employer. In column (3), we can see that middle-aged furloughed workers are the most likely to have their pay topped up. The coefficient on public sector workers is 0.252 , around half the mean value. Furloughed public sector workers are significantly more likely to have their pay topped up than furloughed private sector workers. However, this is not due to their union coverage. Unionized workers were actually less likely to have their pay topped up. There is a U-shaped profile in firm size, with the smallest and largest firms the most likely to top up furloughed workers wages. Higher skilled workers with more tenure were more likely to have wages topped up.

In column (4), we again include quintiles of permanent income, showing that workers with higher incomes were more likely to have their wages topped up. Given the cap at 2,500 per month, had these furloughed workers not had their salaries topped up, they would have seen far more dramatic declines in incomes than lower earning furloughed workers.

\footnotetext{
${ }^{25}$ This refers to workers who despite being furloughed, saw no change from their normal rates of pay. Workers whose pay is partially but not fully topped up will not be included.
} 
Table 7: Earnings changes and furlough across the earnings distribution

\begin{tabular}{|c|c|c|c|c|}
\hline & (1) & (2) & (3) & (4) \\
\hline Furloughed & $\begin{array}{c}-0.150^{* * *} \\
(0.00)\end{array}$ & & $\begin{array}{c}-0.154^{* * *} \\
(0.01)\end{array}$ & \\
\hline Furloughed (No top-up) & & $\begin{array}{c}-0.237^{* * *} \\
(0.00)\end{array}$ & & $\begin{array}{c}-0.223^{* * *} \\
(0.01)\end{array}$ \\
\hline Furloughed (Top-up) & & $\begin{array}{c}-0.087^{* * *} \\
(0.00)\end{array}$ & & $\begin{array}{c}-0.086^{* * *} \\
(0.00)\end{array}$ \\
\hline Earnings (interactions): & & & & \\
\hline Q2 × Furloughed & & & $\begin{array}{l}0.004 \\
(0.01)\end{array}$ & \\
\hline Q3 $\times$ Furloughed & & & $\begin{array}{l}0.007 \\
(0.01)\end{array}$ & \\
\hline Q4 $\times$ Furloughed & & & $\begin{array}{l}0.010 \\
(0.01)\end{array}$ & \\
\hline Q5 $\times$ Furloughed & & & $\begin{array}{l}-0.007 \\
(0.01)\end{array}$ & \\
\hline Q2 $\times$ Furloughed (No top-up) & & & & $\begin{array}{c}-0.018^{*} \\
(0.01)\end{array}$ \\
\hline Q3 $\times$ Furloughed (No top-up) & & & & $\begin{array}{l}0.003 \\
(0.01)\end{array}$ \\
\hline Q4 × Furloughed (No top-up) & & & & $\begin{array}{c}-0.022^{* *} \\
(0.01)\end{array}$ \\
\hline Q5 $\times$ Furloughed (No top-up) & & & & $\begin{array}{c}-0.079^{* * *} \\
(0.01)\end{array}$ \\
\hline Dep var mean & 0.006 & 0.006 & 0.006 & 0.006 \\
\hline R-squared & 0.088 & 0.108 & 0.088 & 0.108 \\
\hline $\mathrm{N}$ & 56,788 & 56,788 & 56,788 & 56,788 \\
\hline
\end{tabular}

Notes: $* \mathrm{p}<0.1, * * \mathrm{p}<0.05, * * * \mathrm{p}<0.01$. Outcome variable is change in log earnings from 2019 to 2020 . All specifications include controls for age, sex, skill level, firm size, public sector, union coverage, plus two-digit industry fixed effects. Years 2019-2020.

Source: ASHE

How is furlough associated with earnings changes? Table 7 contains coefficient estimates from a set of regressions where the outcome variable is the change in log earnings between 2019 and 2020. Unsurprisingly, in column (1) we see that being furloughed is associated with a $15 \log$ point drop in earnings. While we include a wide set of controls including two-digit industry fixed effects, we do not claim this to be causal, as there will be strong selection into which types of workers are chosen for furlough. In column (2), furlough is split into those whose employer tops up their salary and those whose do not. Even among workers whose salary is topped up, there is a greater fall in earnings than in non-furloughed workers. This could be selection (on earnings trajectory), or could be due to employers mis-interpreting the question. In column (3), we interact furlough with permanent earnings. All interactions are estimated precisely and are insignificantly different to zero. The zero coefficients here are interesting, as they suggest that the earnings drop associated 
with being furloughed does not differ across workers of different permanent incomes.

This is capturing two offsetting effects. While furloughed workers of higher incomes are more likely to have their salaries topped up by employers, among the minority whose employers do not top up their salaries, the income loss is substantial as they are paid the maximum furlough level of GBP 2,500 per month. This is shown through the interactions in column (4). Workers of higher permanent incomes who do not have their salaries topped up see a far greater fall in earnings from 2019-2020.

The furlough scheme is the first of its kind in the UK. While it is challenging to assess the causal impact of the introduction of the furlough scheme on earnings inequality and volatility, we can see clearly here that those who are furloughed receive a substantial earnings shock on average, and that those who were already low earners are most likely to be furloughed. However, given the economic context, it has undoubtedly dampened the employment effects of the COVID-19 shock. In a counterfactual without furlough, these furloughed workers would likely have been laid off, so the effect of furlough is likely to have reduced overall inequality.

\subsection{Firm-level shocks, earnings and hours}

Having explored the role of aggregate shocks, we now turn to the transmission of firm-specific shocks to workers. To do so, we run a series of earnings regressions, in which the measure of firmlevel performance is log value added per worker, consistent with the existing literature. Concerns over measurement error and endogeneity, lead us to report both OLS and a set of IV estimates. The results are shown in Table 8. Columns (1) to (4) use log weekly earnings as the outcome variable. Panel (a) shows the OLS estimates and Panel (b) the IV estimates.

In column (1) the instrument is the log of the average value added per worker among all the firms in each firm's 3-digit industry, excluding the firm's own measure. This leave-out mean specification is common in the rent-sharing literature, and uses industry-level productivity shocks to instrument for firm-level productivity shocks. The instrument is strong, delivering an F-statistic of 35. The IV coefficient is 0.065 , an order of magnitude higher than the OLS estimate of 0.007. This large rise in the coefficient when comparing OLS and IV is common in the literature. For example, Card, F. Devicienti, and Maida (2014) using matched worker-firm Italian data report an OLS elasticity of 0.008 and an IV estimate of 0.029. As this is the most common approach in the literature and we are able to use the largest sample for this instrument, we consider the IV estimate from column (1) as our baseline specification.

In column (2), an alternative instrument is used. We use the value added estimate from FAME data to instrument our primary measure of value added, which comes from the ARD. The sample is smaller here, as our matched FAME sample contains only a subset of firms in the ARD. If 
measurement error is indeed an issue, and we assume the measurement error in the ARD and FAME are uncorrelated, we can use the FAME-based measure as an instrument to remove the measurement error in the ARD-based measure. The IV estimate however is similar to that of column (1), at 0.062. This is consistent with measurement error being the issue that is addressed via instruments of these types, rather than endogeneity.

In column (3), we use the lagged value added per worker as an instrument. This delivers a lower point estimate, of 0.028 . Once again however, the qualitative pattern of the IV estimate being substantially larger than the OLS estimate is maintained. In column (4), we jointly include all three instruments. Hansen's overidentification test delivers a p-value of 0.672 , so we cannot reject the null that the overidentification restrictions are valid. The estimated coefficient is 0.061 , close to our baseline estimate.

Columns (5)-(8) replicate columns (1)-(4) but with hours as the outcome. Whilst the IV estimates are imprecisely estimated, and often insignificantly different from zero, the point estimates suggest that perhaps a quarter of the response of weekly wages to firm-level shocks is coming through an hours response. The ratio of the hours and earnings effects is close to that which we found when estimating responses to aggregate shocks above.

Overall, the results suggest that wages are moderately responsive to firm-level shocks. IV estimates are significantly larger than the OLS estimates, and the evidence suggests that this is a result of measurement error in the firm-level measure of value-added per worker. Even though the IV estimates are larger, they are substantially smaller than the elasticity estimates for aggregatelevel shocks of around 0.4, suggesting that workers are significantly more exposed to aggregate shocks than firm-level ones. This highlights how aggregate shocks like COVID-19 can have far larger impacts on employee earnings than firm-level shocks, and hence the importance of using long panels of micro-data spanning several recessions to estimate this macro response.

\section{Conclusion}

In this paper we start by using an employer-based administrative dataset on earnings and hours to set out the key patterns in UK earnings dynamics from 1975 to 2020, with a particular focus on the recent COVID-19 shock. Consistent with previous work, we demonstrate a significant rise in earnings inequality throughout most of the period, with a leveling off in more recent years. We then investigate the effect of aggregate shocks, finding that earnings and hours are procyclical. Exploiting our long panel of data from 1975 to 2020 we then investigate the response of earnings to business cycles. We find wide heterogeneity in the exposure of different types of workers to aggregate shocks. Employees who are younger, male, lower-skilled, non-union, and working in smaller private sector firms show the largest earnings response to recessions. The qualitative patterns of 
Table 8: Rent-sharing estimates

(a) OLS

\begin{tabular}{lcccccccc}
\hline & $(1)$ & $(2)$ & $(3)$ & $(4)$ & $(5)$ & $(6)$ & $(7)$ & $(8)$ \\
\hline $\log (\mathrm{VAPW})$ & $0.007^{* * *}$ & $0.009^{* * *}$ & $0.006^{* *}$ & $0.006^{* * *}$ & $0.004^{* * *}$ & $0.004^{* *}$ & $0.005^{* * *}$ & $0.006^{* * *}$ \\
& $(0.002)$ & $(0.002)$ & $(0.003)$ & $(0.002)$ & $(0.001)$ & $(0.002)$ & $(0.001)$ & $(0.001)$ \\
\hline $\mathrm{N}$ & 597,943 & 331,296 & 486,088 & 281,996 & 596,515 & 331,148 & 485,511 & 281,934 \\
\hline
\end{tabular}

(b) IV

\begin{tabular}{lcccccccc}
\hline & $(1)$ & $(2)$ & $(3)$ & $(4)$ & $(5)$ & $(6)$ & $(7)$ & $(8)$ \\
\hline $\log (\mathrm{VAPW})$ & $0.065^{* * *}$ & $0.062^{* * *}$ & $0.028^{* * *}$ & $0.061^{* *}$ & 0.015 & $0.016^{*}$ & 0.005 & $0.018^{*}$ \\
& $(0.020)$ & $(0.017)$ & $(0.011)$ & $(0.024)$ & $(0.011)$ & $(0.009)$ & $(0.006)$ & $(0.009)$ \\
\hline Dep var mean & 6.115 & 6.073 & 6.119 & 6.084 & 3.535 & 3.539 & 3.535 & 3.543 \\
$\mathrm{~N}$ & 597,943 & 331,296 & 486,088 & 281,996 & 596,515 & 331,148 & 485,511 & 281,934 \\
F-stat & 35.120 & 43.752 & 63.840 & 14.969 & 34.949 & 43.767 & 65.539 & 14.961 \\
Hansen p & & & & 0.672 & & & & 0.645 \\
\hline
\end{tabular}

Notes: Dependent variable is log weekly earnings in columns (1)-(4) and log weekly hours in columns (5)-(8). All specifications include firm-worker match fixed effects. The instruments used are (a) average log value added in firm's 3-digit industry excluding the own-firm observation (the leave-out mean), columns (1) and (5); (b) value-added measure from alternative FAME dataset, columns (2) and (6); (c) lagged value added, columns (3) and (7); and (d) all instruments included, columns (4) and (8). Standard errors clustered by firm.

Source: ASHE

earnings changes across workers observed in the COVID-19 recession are broadly as predicted using the previously estimated exposures and size of the GDP shock. This suggests the COVID-19 recession in terms of its impact responses was relatively similar to those that have gone before, but the GDP shock was far larger in absolute size. Compared to aggregate shocks, we find a relatively small role of firm-specific shocks, suggesting macro shocks play an outsized role in individual earnings dynamics. 


\section{References}

Adams-Prassl, Abi et al. (2020). "Inequality in the impact of the coronavirus shock: Evidence from real time surveys". en. In: Journal of Public Economics, p. 33.

Adams-Prassl, Abi et al. (2020). "Furloughing*”. en. In: Fiscal Studies 41.3._eprint: https://onlinelibrary.wiley.com/ 5890.12242, pp. 591-622. ISSN: 1475-5890. DOI: https : //doi .org/10.1111/1475-5890. 12242. URL: http: //onlinelibrary.wiley.com/doi/abs/10 .1111/1475-5890.12242 (visited on 03/03/2021).

Alon, Titan et al. (Apr. 2020). The Impact of COVID-19 on Gender Equality. en. Tech. rep. w26947. National Bureau of Economic Research. DOI: 10 . 3386/w26947. URL: http: / / www . nber . org/papers/w26947 (visited on 03/03/2021).

Backhouse, Roger E. (Aug. 2010). “The Macroeconomics of Margaret Thatcher”. en. In: Journal of the History of Economic Thought. Publisher: Taylor \& Francis Group. ISSN: 1001-8565. URL: http : / / www . tandfonline . com / doi / abs / 10 . 1080 / 104277102200004767 (visited on 03/02/2021).

Bell, Brian, Nicholas Bloom, and Jack Blundell (2021). "Income Dynamics in the United Kingdom 1975-2020”. In.

Bell, Brian, Mihai Codreanu, and Stephen Machin (2020). "What Can Previous Recessions Tell Us About The Covid-19 Downturn?” en. In: CEP Covid-19 Analysis Series 7, p. 28.

Bell, Brian and John Van Reenen (2014). "Bankers and Their Bonuses”. en. In: The Economic Journal 124.574._eprint: https://onlinelibrary.wiley.com/doi/pdf/10.1111/ecoj.12101, F1-F21. ISSN: 1468-0297. DOI: https ://doi .org/10.1111/ecoj .12101. URL: http: //onlinelibrary . wiley.com/doi/abs/10.1111/ecoj.12101 (visited on 12/15/2020).

Berman, Eli, John Bound, and Stephen Machin (Nov. 1998). "Implications of Skill-Biased Technological Change: International Evidence*”. In: The Quarterly Journal of Economics 113.4, pp. 1245-1279. ISSN: 0033-5533. DOI: 10 . 1162 / 003355398555892. URL: https : / / doi . org/10.1162/003355398555892 (visited on 03/03/2021).

Bird, Derek (2004). "Methodology for the 2004 Annual Survey of Hours and Earnings". en. In: p. 8.

Blanchflower, David G. and Alex Bryson (2008). "Union decline in Britain”. In: IZA Discussion Paper 3426.

Blundell, Jack, Stephen Machin, and Maria Ventura (2020). "Covid-19 and the Self-Employed: Six Months into the Crisis". en. In: CEP Covid-19 Analysis Series 12, p. 14.

Boeri, Tito et al. (Feb. 2020). "Solo Self-Employment and Alternative Work Arrangements: A Cross-Country Perspective on the Changing Composition of Jobs”. en. In: Journal of Economic 
Perspectives 34.1, pp. 170-195. ISSN: 0895-3309. DOI: 10 . 1257 / jep . 34 . 1 . 170. URL: https: //pubs . aeaweb.org/doi/10.1257/jep. 34.1 .170 (visited on 06/05/2020).

Brewer, Mike (June 2019). What Do We Know and What Should We Do About Inequality? en. Google-Books-ID: iXmaDwAAQBAJ. SAGE. ISBN: 978-1-5264-8133-7.

Bryson, Alex and John Forth (Jan. 2011). "Trade Unions”. en. In: The Labour Market in Winter: The State of Working Britain. Google-Books-ID: YOgIih27uoEC. OUP Oxford. ISBN: 978-019-958737-7.

Cappellari, Lorenzo and Stephen P. Jenkins (Oct. 2014). "Earnings and labour market volatility in Britain, with a transatlantic comparison”. en. In: Labour Economics 30, pp. 201-211. ISSN: 09275371. DOI: 10 . 1016/ j . labeco . 2014 .03 .012. URL: https : / / linkinghub . elsevier.com/retrieve/pii/S0927537114000414 (visited on 02/19/2019).

Card, D., F. Devicienti, and A. Maida (Jan. 2014). "Rent-sharing, Holdup, and Wages: Evidence from Matched Panel Data". en. In: The Review of Economic Studies 81.1, pp. 84-111. ISSN: 0034-6527, 1467-937X. DOI: 10 . 1093/restud/rdt030. URL: https : / / academic . oup . $\mathrm{com} / \mathrm{restud} / \mathrm{article-10okup/doi/10.1093/restud/rdt030} \mathrm{(visited} \mathrm{on} \mathrm{02/10/2020).}$

Crawford, Claire, Wenchao Jin, and Helen Simpson (June 2013). "Productivity, Investment and Profits during the Great Recession: Evidence from UK Firms and Workers*”. en. In: Fiscal Studies 34.2, pp. 153-177. ISSN: 01435671. DOI: 10 .1111/ j .1475-5890 . 2013 . 12002 . x. URL: http : / / doi . wiley . com/10 .1111/ j . 1475-5890.2013 . 12002 . x (visited on 12/12/2019).

Cribb, Jonathan, Carl Emmerson, and Luke Sibieta (2014). Public sector pay in the UK. R97. IFS Reports, Institute for Fiscal Studies. URL: https : / / www . econstor . eu / handle / 10419 / 119787 (visited on 04/25/2017).

Datta, Nikhil, Giulia Giupponi, and Stephen Machin (July 2019). "Zero-hours contracts and labour market policy”. In: Economic Policy 34.99, pp. 369-427. ISSN: 0266-4658. DOI: 10 . 1093 / epolic/eiz008. URL: https: //doi .org/10.1093/epolic/eiz008 (visited on 12/17/2020).

Devereux, Paul J. and Robert A. Hart (Oct. 2006). "Real Wage Cyclicality of Job Stayers, WithinCompany Job Movers, and Between-Company Job Movers". en. In: ILR Review 60.1, pp. 105119. ISSN: 0019-7939, 2162-271X. DOI: 10 . 1177 / 001979390606000106. URL: http : / / journals . sagepub. com/doi/10.1177/001979390606000106 (visited on 03/31/2020).

Devicienti, Francesco (May 2011). "Estimating poverty persistence in Britain". en. In: Empirical Economics 40.3, pp. 657-686. ISSN: 1435-8921. DOI: 10.1007/s00181-010-0350-2. URL: https : //doi .org/10.1007/s00181-010-0350-2 (visited on 03/03/2021).

Dickens, Richard (2000). "The Evolution of Individual Male Earnings in Great Britain: 1975-95". en. In: The Economic Journal 110.460, pp. 27-49. ISSN: 1468-0297. DOI: 10 . 1111/1468- 
0297 . 00489. URL: https : / / onlinelibrary . wiley . com / doi / abs / 10 . 1111/1468 0297.00489 (visited on 06/29/2018).

Dickens, Richard and Abigail McKnight (2008). "Changes in earnings inequality and mobility in Great Britain 1978/9-2005/6". en. In: CEP Occasional paper 21. OCLC: 645694730. URL: http: //cep.lse.ac.uk/pubs/download/occasional/op021.pdf (visited on 03/03/2021).

Dolton, Peter, Chiara Rosazza Bondibene, and Jonathan Wadsworth (2010). "The UK National Minimum Wage in Retrospect*”. en. In: Fiscal Studies 31.4._eprint: https://

onlinelibrary.wiley.com/doi/pdf/10.1111/5890.2010.00123.x, pp. 509-534. ISSN: 1475-5890. DOI: https://doi.org/10.1111/j.1475-5890.2010.00123.x. URL: http://onlinelibrary.wiley.com/ doi/abs/10.1111/j.1475-5890.2010.00123.x (visited on 03/02/2021).

Dolton, Peter, Chiara Rosazza-Bondibene, and Jonathan Wadsworth (Jan. 2011). "The Regional Labour Market in the UK". en. In: The Labour Market in Winter. Google-Books-ID: YOgIih27uoEC. OUP Oxford. ISBN: 978-0-19-958737-7.

Dustmann, Christian and Tommaso Frattini (Nov. 2014). "The Fiscal Effects of Immigration to the UK”. en. In: The Economic Journal 124.580, F593-F643. ISSN: 0013-0133, 1468-0297. DOI: 10.1111/ecoj . 12181. URL: https: / /academic . oup.com/ej/article/124/580/F593F643/5076967 (visited on 03/02/2021).

Elsby, Michael W. L., Donggyun Shin, and Gary Solon (Jan. 2016). "Wage Adjustment in the Great Recession and Other Downturns: Evidence from the United States and Great Britain". en. In: Journal of Labor Economics 34.S1, S249-S291. ISSN: 0734-306X, 1537-5307. DOI: 10 . 1086/682407. URL: https : / / www . journals . uchicago . edu / do i / 10 . 1086/682407 (visited on 07/18/2019).

Eurostat (2021). Statistics Explained: Migration and migrant population statistics. Tech. rep. URL: https : / / ec . europa . eu / eurostat / statistics - explained / pdfscache / 1275 . pdf (visited on 03/02/2021).

Fetzer, Thiemo (Nov. 2019). "Did Austerity Cause Brexit?" en. In: American Economic Review 109.11, pp. 3849-86. ISSN: 0002-8282. DOI: 10.1257/aer.20181164 URL: http: //www . aeaweb.org/articles?fbclid=IwAR3JH9JROKMqDnySUojv_zUfeBYaQhs JXevD8xeA8IWGeE9GS8oSinegRk\& id=10.1257\%2Faer.20181164 (visited on 03/02/2021).

Goos, Maarten and Alan Manning (2007). "Lousy and lovely jobs: The rising polarization of work in Britain". In: The review of economics and statistics 89.1, pp. 118-133. URL: http: //www . mitpress journals . org/doi/abs/10.1162/rest.89.1.118 (visited on 04/24/2017).

Gregg, Paul, Stephen Machin, and Mariña Fernández-Salgado (May 2014). "Real Wages and Unemployment in the Big Squeeze". en. In: The Economic Journal 124.576, pp. 408-432. ISSN: 00130133. DOI: 10.1111/ecoj .12139. URL: https : / /academic . oup.com/ej/article/ 124/576/408-432/5077332 (visited on 07/18/2019). 
Guvenen, Fatih, Fatih Karahan, et al. (2015). What do data on millions of US workers reveal about life-cycle earnings risk? Tech. rep. National Bureau of Economic Research.

Guvenen, Fatih, Sam Schulhofer-Wohl, et al. (May 2017). "Worker Betas: Five Facts about Systematic Earnings Risk". en. In: American Economic Review 107.5, pp. 398-403. ISSN: 0002-8282. DOI: 10 . 1257 / aer . p20171094. URL: http : / pubs . aeaweb . org/doi / 10 . 1257/aer . p20171094 (visited on 04/29/2019).

Hay, Colin (2009). "The Winter of Discontent Thirty Years On”. en. In: The Political Quarterly 80.4._eprint: https://onlinelibrary.wiley.com/doi/pdf/10.1111/j.1467-923X.2009.02052.x, pp. 545552. ISSN: 1467-923X. DOI: https : //doi .org/10.1111/j .1467-923X . 2009.02052 .x. URL: http: / / onlinelibrary . wiley . com/doi / abs / 10 . 1111/ j . 1467-923X . 2009 . 02052.x (visited on 03/02/2021).

Herz, Benedikt van Rens (Feb. 2020). "The labor market in the UK, 2000-2019". en-US. In: IZA World of Labor. DOI: 10.15185/izawol . 422. URL: https : / wol .iza .org/articles / the-labor-market-in-the-uk/long (visited on 12/17/2020).

Hills, John et al. (2010). "An Anatomy of Economic Inequality in the UK - Report of the National Equality Panel”. en. In: CASE report 60, p. 476. ISSN: 1465-3001.

Jenkins, Stephen P. (July 2011a). Changing Fortunes: Income Mobility and Poverty Dynamics in Britain. en. Google-Books-ID: nnzZ4eeaGjoC. OUP Oxford. ISBN: 978-0-19-161994-6.

- (Oct. 2011b). "Has the Instability of Personal Incomes been Increasing?" en. In: National Institute Economic Review 218.1, R33-R43. ISSN: 0027-9501, 1741-3036. DOI: 10 . 1177 / 002795011121800104. URL: http:// journals . sagepub. com/doi/10.1177/002795011121800104 (visited on 05/21/2018).

Kalwij, Adriaan S. and Rob Alessie (Sept. 2007). "Permanent and transitory wages of British men, 1975-2001: year, age and cohort effects". en. In: Journal of Applied Econometrics 22.6, pp. 1063-1093. ISSN: 08837252, 10991255. DOI: 10 .1002/ jae . 941. URL: http: //doi . wiley. com/10.1002/jae.941 (visited on 06/29/2018).

Kerr, Sari Pekkala et al. (2017). "High-skilled migration and agglomeration". In: Annual Review of Economics 0. URL: http: // www . annualreviews . org/doi / abs/10.1146/annureveconomics-063016-103705 (visited on 08/23/2017).

Krueger, Alan B (2017). "Where Have All the Workers Gone? An Inquiry into the Decline of the U.S. Labor Force Participation Rate". In: Brookings papers on economic activity 2017.2, pp. 187. ISSN: 0007-2303. DOI: 10.1353/eca. 2017.0012. URL: https : / www.ncbi .nlm.nih . gov/pmc/articles/PMC6364990/ (visited on 03/02/2021).

LPC (2020a). National Minimum Wage: Low Pay Commission Report 2019. en. OCLC: 1140138902. ISBN: 978-1-5286-1669-0. 
LPC (2020b). The National Minimum Wage in 2020 - Uprating Report April 2020. URL: https : / / assets . publishing . service . gov . uk / government / uploads / system / uploads / attachment_data/file/877174/LPC_2020_uprating_report.pdf (visited on 03/02/2021). Machin, Stephen (Dec. 2000). "Union Decline in Britain". en. In: British Journal of Industrial Relations 38.4, pp. 631-645. ISSN: 0007-1080, 1467-8543. DOI: 10.1111/1467-8543.00183. URL: https: //onlinelibrary.wiley.com/doi/abs/10.1111/1467-8543.00183 (visited on $12 / 17 / 2020$ ).

- (Jan. 2011). "Changes in UK Wage Inequality Over the Last Forty Years". en. In: The Labour Market in Winter: The State of Working Britain. Google-Books-ID: YOglih27uoEC. OUP Oxford. ISBN: 978-0-19-958737-7.

Machin, Stephen and John Van Reenen (1998). "Technology and changes in skill structure: evidence from seven OECD countries". In: The Quarterly Journal of Economics 113.4, pp. 12151244. URL: http://qje . oxfordjournals . org/content/113/4/1215. short (visited on 04/24/2017).

Manning, Alan and Barbara Petrongolo (2008). "The Part-Time Pay Penalty for Women in Britain*". en. In: The Economic Journal 118.526, F28-F51. ISSN: 1468-0297. DOI: $10.1111 / \mathrm{j} .1468-$ 0297.2007.02115.x. URL: https://onlinelibrary.wiley.com/doi/abs/10.1111/j. 1468-0297. 2007.02115.x (visited on 07/26/2019).

Medina, Leandro and Friedrich Schneider (2018). "Shadow Economies Around the World: What Did We Learn Over the Last 20 Years". In: IMF working paper WP/18/17.

Nickell, Stephen and Glenda Quintini (2003). "Nominal wage rigidity and the rate of inflation*". en. In: The Economic Journal 113.490._eprint: https://onlinelibrary.wiley.com/doi/pdf/10.1111/14680297.t01-1-00161, pp. 762-781. ISSN: 1468-0297. DOI: https://doi .org/10.1111/14680297.t01-1-00161. URL: http://onlinelibrary.wiley.com/doi/abs/10.1111/14680297.t01-1-00161 (visited on 03/02/2021).

Petrongolo, Barbara (Apr. 2019). "The gender gap in employment and wages". en. In: Nature Human Behaviour 3.4, pp. 316-318. ISSN: 2397-3374. DOI: 10 . 1038/s41562-019-0558-x. URL: http: //www . nature.com/articles/s41562-019-0558-x (visited on 01/03/2020).

Pintér, Gábor (Feb. 2019). "House Prices and Job Losses". en. In: The Economic Journal 129.618, pp. 991-1013. ISSN: 0013-0133, 1468-0297. DOI: 10 . 1111 / ecoj . 12613. URL: https : / / academic. oup.com/ej/article/129/618/991/5289555 (visited on 03/02/2021).

Ramos, Xavier (2003). "The Covariance Structure of Earnings in Great Britain, 1991-1999”. en. In: Economica 70.278, pp. 353-374. ISSN: 1468-0335. DOI: 10.1111/1468-0335.00328. URL: https://onlinelibrary.wiley.com/doi/abs/10.1111/1468-0335.00328 (visited on 06/29/2018). 
Ritchie, Felix (2005). Accessing the new earnings survey panel: Efficient techniques and applications. PhD dissertation. University of Sterling.

Sabelhaus, John and Jae Song (2010). "The great moderation in micro labor earnings". In: Journal of Monetary Economics 57.4. Publisher: Elsevier, pp. 391-403.

Schaefer, Daniel and Carl Singleton (June 2019). "Recent Changes in British Wage Inequality: Evidence from Large Firms and Occupations: Recent changes in British wage inequality". en. In: Scottish Journal of Political Economy. ISSN: 00369292. DOI: 10.1111/s jpe.12225. URL: http://doi.wiley.com/10.1111/sjpe. 12225 (visited on 07/10/2019).

Summers, Andy et al. (Sept. 2020). Importing inequality: immigration and the top 1 percent. en. Tech. rep. The IFS. DOI: 10 . 1920 / wp . ifs . 2020 . 3120. URL: https : / / ifs . org . uk / publications/15037 (visited on 12/15/2020). 


\section{A Background on the UK labor market}

\section{A.1 Macroeconomic trends}

Figure 10 shows the evolution of annual real GDP growth, inflation and unemployment over the period, which saw four recessions (1980-81, 1990-91, 2008-09 and 2020). The first five years of the period was a particularly volatile period. The 'winter of discontent' in 1978-79 saw widespread industrial action, with the government clashing with unions in an attempt to bring high inflation under control (Hay, 2009). The outcomes of these wage negotiations and the double digit inflation rates combine to deliver unusual and highly unstable wage patterns over the period, which will be evident in the wage data presented in Section 3.

To combat inflation, in 1979 Margaret Thatcher's newly-elected conservative government tightened monetary and fiscal policy (Backhouse, 2010). This led to the 1980-81 recession, which was swiftly followed by high unemployment for most of the 1980s, peaking at $12 \%$ in 1984 . Sterling appreciated significantly, and the manufacturing sector was struck particularly severely. Following a sharp rise in union power throughout the preceding decade, Thatcher's government was successful in reducing the power of unions (Machin (2000), Blanchflower and Bryson (2008)).

The mid to late 1980s saw high economic growth and rising inflation. Low interest rates led to a boom in the housing market and income tax cuts helped fuel an increase in consumer spending. In 1990 the boom turned to bust, the economy again entering a recession. This second recession was shallower than that of 1980-81, with unemployment peaking at around 10\% between 1992 and 1994. Unlike the previous crisis, house prices crashed, losing 10\% of their value in 1990 (Pintér, 2019).

The 'great moderation' period from the early 1990s into the late 2000s is characterized by low inflation, falling unemployment and steady growth. Relative to the US and many other European countries, the UK did not experience an early 2000s recession. Throughout the period, output per hour worked grew steadily at a rate of approximately $2 \%$ (Herz, 2020).

The UK did however experience a sharp downturn in the Great Recession of 2008-9. The economy contracted by over 5\%, representing the deepest recession since the Second World War. Given the scale of this recession, Figure 10 shows the employment effects to be relatively mild in the short term. While employment held up, wages and productivity stagnated in the decade that followed (Herz (2020), Crawford, Jin, and Simpson (2013)). During the 2010s there was a substantial fiscal tightening. The Conservative government's austerity programme consisted of sustained reductions in public spending and tax rises (Fetzer, 2019). This included cuts to public services and a public sector pay freeze from 2011 and 2013, followed by commitments to wage restraint since then (Cribb, Emmerson, and Sibieta, 2014).

At the time of writing, we are still experiencing the 2020 COVID-19 recession. In terms of 
Figure 10: Macroeconomic trends 1975-2020

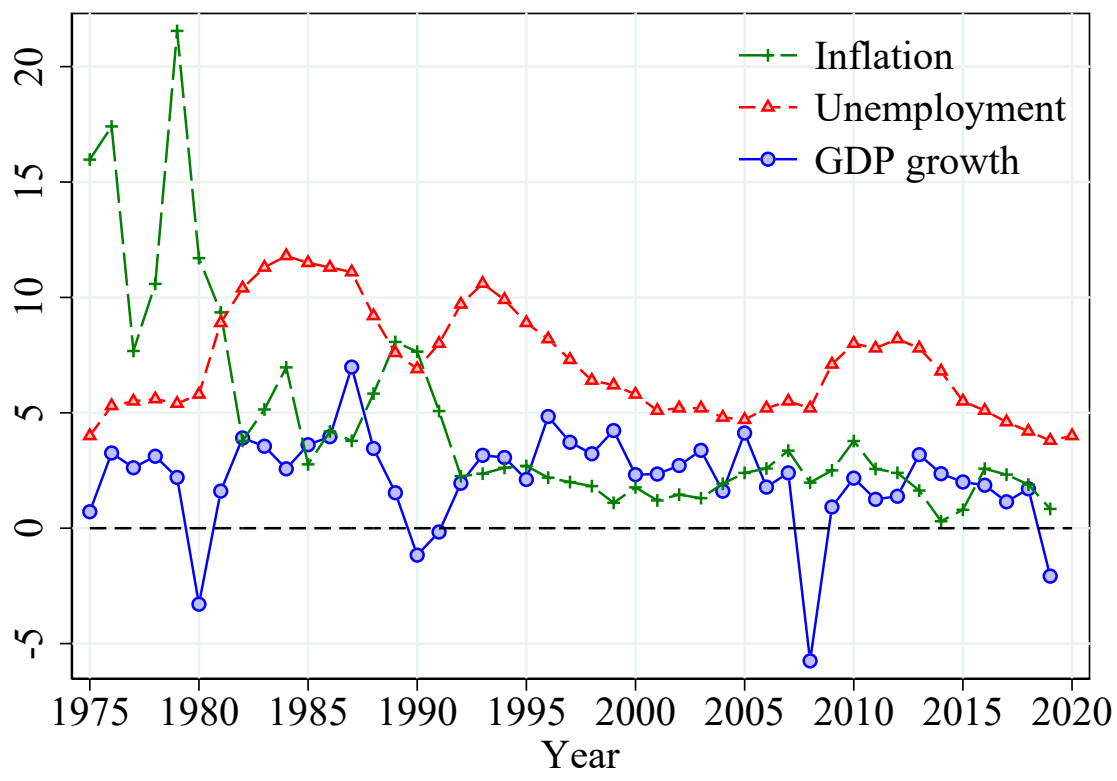

Notes: GDP growth given in real terms. GDP growth and unemployment rate refer to Q1 of each year, inflation to Q2. Growth rates for year $t$ refer to changes from $t$ to $t+1$.

Source: Office for National Statistics, Federal Reserve Bank of St. Louis

aggregate growth, the UK has been particularly negatively affected. Figure 10 shows data up to Q1 2020, at which point the fall looks relatively mild. In Q2 2020, real GDP was 21.7\% lower than it was a year earlier, dwarfing all previous downturns. For 2020 as a whole, GDP declined by $9.9 \%$ - one of the largest drops across the OECD. As elsewhere, the government have responded by introducing unprecedented labor market support programmes. Most relevant to the current paper is the furlough scheme, in which the government provides employers with $80 \%$ of employee wages, on the condition that the worker is not performing any work at the time.

Another key part of the story of the UK's economy over the period is migration. From 19751995, net migration to the UK was stable. Since then, and particularly since 2004, net migration has increased. In the years that followed the expansion of the EU in 2004, the UK saw high immigration from Central and Eastern Europe (Dustmann and Frattini, 2014). Despite this, the share of foreignborn population in the UK is comparable to that of other European countries (Eurostat, 2021). Since the EU referendum in 2016, the number of EU workers moving to the UK has fallen, but the number of non-EU workers has risen. Kerr et al. (2017) have shown that the UK is a particularly attractive destination for high-skilled migrants. More recent work has used tax data to show that almost all (85\%) of the growth in the UK top $1 \%$ income share over the past 20 years can be attributed to migration (Summers et al., 2020). Looking ahead, the UK's exit from the EU is likely to change the UK's labor market substantially. European immigrants constitute a large share of workers in 
particular sectors and occupations, and any worsening in the UK's access to international markets may have substantial effects on some workers.

In terms of labor force participation, The UK has not seen the long decline found in the US (Krueger, 2017). Over the period under study, female labor force participation increased from $55 \%$ to $72 \%{ }^{26}$ The gender pay gap, as in the US, has been falling over the period (Petrongolo, 2019). Until very recently, part-time work has been rare among male workers, so the part-time pay penalty plays an important role. Manning and Petrongolo (2008) report the gap to have widened greatly over the period of study, and that it can be mostly explained by worker characteristics and occupational differences.

The UK has particularly strong geographical inequalities. Many of the highest-skill jobs, particularly in professional services, are found in London and the South-East. Previous industrial heartlands of the Midlands, South Wales, the North West and the North East have lower wages and high unemployment. While narrower today than in the 1980s, (Dolton, Rosazza-Bondibene, and Wadsworth, 2011) show persistent differences in wages and employment by area.

\section{A.2 Labor market institutions}

Turning from macroeconomic trends to labor market institutions, the UK is typically thought to occupy a relatively distinct space between US and European-style labor markets. Compared to elsewhere in Europe, UK workers are provided little employment protection. Summarizing regulation of individual worker dismissals, the OECD scores only the US, Switzerland and Canada as offering less protection. ${ }^{27}$ A key labor market policy shift came in 1999 with the introduction of a national minimum wage. ${ }^{28}$ Initially, this was low by international standards. It has risen substantially in real terms and for most workers in 2020 was $60 \%$ of the median full-time hourly wage (Dolton, Bondibene, and Wadsworth, 2010; LPC, 2020b). As a proportion of median full-time wages, it is now among the highest in the world.

As discussed in the previous section, aggregate union density begun a long downward trend from 1980 onwards, a trend that occurs across sectors but most notably in manufacturing. The public sector has remained highly unionized despite the decline in the private sector. While union density has fallen dramatically, the decline in coverage of union-negotiated collective agreements has been significantly less precipitous (Bryson and Forth, 2011).

The labor market has seen a rise in the share of workers in 'alternative working arrangements'. Most prominent is the rise in self-employment, particularly the solo self-employed (Boeri et al., 2020). As of 2019, the self-employed constitute $15 \%$ of aggregate employment, and recent survey

\footnotetext{
${ }^{26}$ Office For National Statistics, Series LF25, accessed online 2nd March 2021.

${ }^{27}$ OECD Indicators of Employment Protection, accessed online 2nd March 2021.

${ }^{28}$ Before this year, there were limited sector-specific minimum wages.
} 
evidence suggests that the COVID-19 crisis has struck the self-employed particularly hard (Blundell, Machin, and Ventura, 2020). The period has also seen growth in Zero Hours Contracts employment contracts in which a worker is not guaranteed any hours and is only paid for work carried out. Datta, Giupponi, and Machin (2019) estimate their prevalence to be at $2.7 \%$ of workers. These workers are covered by many of the same regulations as permanent employees. Unlike Italy, France and Spain, in the UK we have not seen extensive use of temporary contracts among workers early on in their careers. Medina and Schneider (2018) estimate the UK's shadow economy to be under $10 \%$ of total employment, small by global and European standards. 


\section{B Additional tables and figures for Section 2}

Table 9: Descriptive Statistics for firm-match samples by year

\begin{tabular}{rrrrrr}
\hline Year & Firms & Workers & \% Match & Employees & VAPW \\
\hline 2002 & 10,176 & 53,855 & 38 & 522 & 36.3 \\
2003 & 9,749 & 54,634 & 38 & 583 & 36.5 \\
2004 & 10,001 & 54,958 & 38.2 & 596 & 41.5 \\
2005 & 9,750 & 56,140 & 37.2 & 612 & 44.2 \\
2006 & 8,561 & 47,414 & 31.2 & 653 & 44.8 \\
2007 & 8,465 & 40,959 & 32.1 & 682 & 50.1 \\
2008 & 8,011 & 43,432 & 34.1 & 819 & 54 \\
2009 & 9,550 & 71,913 & 46.1 & 992 & 50.6 \\
2010 & 8,554 & 69,747 & 44.2 & 1,045 & 55.7 \\
2011 & 8,950 & 72,948 & 44.1 & 1,010 & 55.3 \\
2012 & 9,124 & 72,359 & 45.5 & 1,026 & 56.8 \\
2013 & 9,115 & 72,954 & 45.5 & 1,032 & 59.8 \\
2014 & 9,245 & 75,485 & 45.6 & 1,046 & 63.8 \\
\hline
\end{tabular}

(a) ARD

\begin{tabular}{rrrrrr}
\hline Year & Firms & Workers & \% Match & Employees & VAPW \\
\hline 2002 & 4,284 & 21,934 & 15.5 & 629 & 29.3 \\
2003 & 5,305 & 32,805 & 22.8 & 765 & 31.6 \\
2004 & 5,204 & 35,379 & 24.6 & 835 & 33.7 \\
2005 & 5,279 & 38,267 & 25.3 & 857 & 36 \\
2006 & 5,475 & 40,360 & 26.6 & 890 & 37.4 \\
2007 & 5,160 & 34,069 & 26.7 & 922 & 40.4 \\
2008 & 5,230 & 34,711 & 27.3 & 942 & 40.1 \\
2009 & 7,181 & 45,657 & 29.3 & 764 & 40.5 \\
2010 & 8,829 & 51,042 & 32.3 & 706 & 42.6 \\
2011 & 9,018 & 54,716 & 33.1 & 725 & 43 \\
2012 & 9,390 & 56,069 & 35.2 & 728 & 44.3 \\
2013 & 9,942 & 58,071 & 36.2 & 698 & 45.1 \\
2014 & 10,324 & 59,825 & 36.1 & 698 & 46.3 \\
2015 & 10,551 & 58,265 & 35.6 & 702 & 47.2 \\
2016 & 10,306 & 55,858 & 35.1 & 706 & 48.2 \\
2017 & 10,020 & 54,412 & 34 & 693 & 49 \\
2018 & 10,379 & 53,605 & 34.2 & 673 & 50 \\
\hline
\end{tabular}

(b) FAME

Notes: Number of matched firms and workers by year for ARD in panel (a) and FAME in panel (b). Employees and value added per worker refers to mean number of employees and mean value added per worker at the firm level in the matched sample. \% match figure includes all workers with non-missing earnings in denominator, including public-sector workers. 
Table 10: Predictors of matching to firm data

\begin{tabular}{|c|c|c|}
\hline & $\begin{array}{c}(1) \\
\text { ARD }\end{array}$ & $\begin{array}{c}(2) \\
\text { FAME }\end{array}$ \\
\hline Female & $\begin{array}{c}-0.070^{* * *} \\
(0.00)\end{array}$ & $\begin{array}{c}-0.064^{* * *} \\
(0.00)\end{array}$ \\
\hline (log)Earnings & $\begin{array}{c}0.008^{* * *} \\
(0.00)\end{array}$ & $\begin{array}{c}-0.021^{\text {*** }} \\
(0.00)\end{array}$ \\
\hline Full-time & $\begin{array}{c}0.042^{* * *} \\
(0.00)\end{array}$ & $\begin{array}{c}0.020^{* * *} \\
(0.00)\end{array}$ \\
\hline Union & $\begin{array}{c}-0.006^{* * *} \\
(0.00)\end{array}$ & $\begin{array}{c}-0.091^{* * *} \\
(0.00)\end{array}$ \\
\hline \multicolumn{3}{|l|}{ Age: } \\
\hline $25-34$ & $\begin{array}{c}0.050^{* * *} \\
(0.00)\end{array}$ & $\begin{array}{c}-0.038^{* * *} \\
(0.00)\end{array}$ \\
\hline $35-44$ & $\begin{array}{c}0.067^{* * *} \\
(0.00)\end{array}$ & $\begin{array}{c}-0.029^{* * *} \\
(0.00)\end{array}$ \\
\hline $45-54$ & $\begin{array}{c}0.076^{* * *} \\
(0.00)\end{array}$ & $\begin{array}{c}-0.024^{* * *} \\
(0.00)\end{array}$ \\
\hline $55-64$ & $\begin{array}{c}0.081^{* * *} \\
(0.00)\end{array}$ & $\begin{array}{c}-0.028^{* * *} \\
(0.00)\end{array}$ \\
\hline \multicolumn{3}{|l|}{ Firm size: } \\
\hline $100-499$ & $\begin{array}{c}0.442^{* * *} \\
(0.00)\end{array}$ & $\begin{array}{c}0.399^{* * *} \\
(0.00)\end{array}$ \\
\hline 500-1999 & $\begin{array}{c}0.727^{* * *} \\
(0.00)\end{array}$ & $\begin{array}{c}0.442^{* * *} \\
(0.00)\end{array}$ \\
\hline $2000+$ & $\begin{array}{c}0.626^{* * *} \\
(0.00)\end{array}$ & $\begin{array}{c}0.506^{* * *} \\
(0.00)\end{array}$ \\
\hline Dep var mean & 0.404 & 0.303 \\
\hline R-squared & 0.399 & 0.299 \\
\hline $\mathrm{N}$ & $1,947,882$ & $2,587,482$ \\
\hline
\end{tabular}

Notes: Outcome variable $=1$ if worker in ASHE successfully matched to firm in ARD (column 1) or FAME (column 2). Column (1) includes years 2002-2014, column (2) years 2002-2018.

Source: ASHE, ARD, FAME 


\section{Additional tables and figures for Section 3}

Table 11: Descriptive Statistics for LX sample by year

\begin{tabular}{rrrrrrrr}
\hline Year & Obs & Fem inc & Male inc & Female \% & \multicolumn{3}{c}{ Age } \\
& & & & & $25-35 \%$ & $36-45 \%$ & $46-55 \%$ \\
\hline 1975 & 37,023 & 326 & 609 & 31.5 & 40.3 & 38.2 & 21.4 \\
1980 & 42,873 & 335 & 637 & 36.2 & 41.3 & 39.4 & 19.3 \\
1985 & 48,785 & 379 & 700 & 38 & 39.6 & 41.8 & 18.5 \\
1990 & 57,790 & 485 & 843 & 41.8 & 41.4 & 41.1 & 17.5 \\
1995 & 55,256 & 523 & 847 & 43.9 & 40.7 & 38.8 & 20.5 \\
2000 & 50,080 & 576 & 936 & 47.1 & 35.6 & 44.5 & 19.9 \\
2005 & 53,395 & 660 & 1,039 & 49.7 & 32.2 & 46.1 & 21.7 \\
2010 & 53,537 & 677 & 986 & 50.9 & 32.8 & 42.1 & 25 \\
2015 & 34,480 & 642 & 896 & 51.6 & 35 & 39.3 & 25.7 \\
\hline
\end{tabular}

(a) Earnings and demographics

\begin{tabular}{ccccccccccr}
\hline Year & \multicolumn{1}{c}{ Percentile } \\
& 1 & 5 & 10 & 25 & 50 & 75 & 90 & 95 & 99 & 99.9 \\
\hline 1975 & 97 & 159 & 222 & 362 & 499 & 647 & 814 & 935 & 1,278 & 1,995 \\
1980 & 78 & 141 & 201 & 358 & 505 & 658 & 840 & 986 & 1,405 & 2,177 \\
1985 & 76 & 144 & 219 & 378 & 539 & 721 & 948 & 1,129 & 1,657 & 2,895 \\
1990 & 87 & 175 & 264 & 432 & 631 & 862 & 1,139 & 1,380 & 2,198 & 4,289 \\
1995 & 84 & 177 & 265 & 435 & 637 & 887 & 1,168 & 1,413 & 2,194 & 4,222 \\
2000 & 94 & 190 & 276 & 457 & 677 & 960 & 1,280 & 1,578 & 2,554 & 4,693 \\
2005 & 116 & 214 & 299 & 498 & 738 & 1,062 & 1,442 & 1,773 & 3,032 & 5,681 \\
2010 & 121 & 215 & 303 & 495 & 727 & 1,042 & 1,395 & 1,724 & 2,752 & 4,917 \\
2015 & 115 & 209 & 286 & 464 & 676 & 965 & 1,298 & 1,572 & 2,429 & 4,149 \\
\hline
\end{tabular}

(b) Earnings percentiles

Notes: Summary statistics for LX sample. All earnings figures are weekly earnings in 2018 USD. Panel (a) gives mean weekly earnings, the share female and the share in each age bracket. Panel (b) gives earnings percentiles for both genders combined for each year.

Source: ASHE 
Table 12: Descriptive Statistics for H sample by year

\begin{tabular}{rccccccr}
\hline Year & Obs & Fem inc & Male inc & Female \% & \multicolumn{1}{c}{ Age } \\
& & & & & $25-35 \%$ & $36-45 \%$ & $46-55 \%$ \\
\hline 1980 & 27,967 & 357 & 656 & 33.3 & 35.5 & 42.6 & 21.9 \\
1985 & 34,779 & 403 & 727 & 35.7 & 33.3 & 45.7 & 21 \\
1990 & 40,057 & 522 & 877 & 38.5 & 35.1 & 44.9 & 19.9 \\
1995 & 41,210 & 559 & 891 & 41.8 & 35 & 42 & 23 \\
2000 & 36,212 & 608 & 969 & 45.2 & 30.2 & 47.5 & 22.3 \\
2005 & 36,467 & 697 & 1,090 & 48.1 & 25.6 & 49.9 & 24.5 \\
2010 & 31,031 & 716 & 1,053 & 49.6 & 26.7 & 45.2 & 28.1 \\
2015 & 24,223 & 685 & 950 & 50.2 & 28.1 & 42.3 & 29.6 \\
\hline
\end{tabular}

(a) Earnings and demographics

\begin{tabular}{ccccccccccr}
\hline Year & \multicolumn{1}{c}{ Percentile } \\
& 1 & 5 & 10 & 25 & 50 & 75 & 90 & 95 & 99 & 99.9 \\
\hline 1980 & 93 & 160 & 235 & 389 & 534 & 685 & 866 & 1,017 & 1,431 & 2,283 \\
1985 & 89 & 163 & 255 & 408 & 574 & 753 & 984 & 1,169 & 1,695 & 2,811 \\
1990 & 108 & 210 & 311 & 474 & 681 & 906 & 1,190 & 1,440 & 2,277 & 4,189 \\
1995 & 102 & 211 & 308 & 474 & 684 & 934 & 1,222 & 1,472 & 2,266 & 4,280 \\
2000 & 117 & 222 & 313 & 494 & 723 & 1,006 & 1,321 & 1,621 & 2,562 & 4,654 \\
2005 & 138 & 247 & 340 & 542 & 794 & 1,119 & 1,499 & 1,834 & 3,111 & 6,076 \\
2010 & 145 & 248 & 346 & 537 & 787 & 1,104 & 1,475 & 1,817 & 2,878 & 4,821 \\
2015 & 141 & 243 & 332 & 507 & 729 & 1,022 & 1,350 & 1,639 & 2,509 & 4,330 \\
\hline
\end{tabular}

(b) Earnings percentiles

Notes: Summary statistics for H sample. All earnings figures are weekly earnings in 2018 USD. Panel (a) gives mean weekly earnings, the share female and the share in each age bracket. Panel (b) gives earnings percentiles for both genders combined for each year.

Source: ASHE 
Figure 11: ASHE coverage

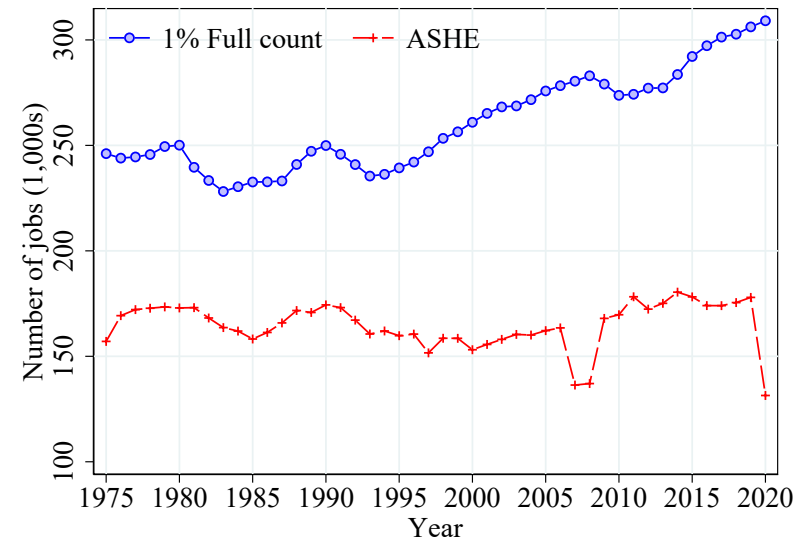

(a) ASHE counts and total jobs

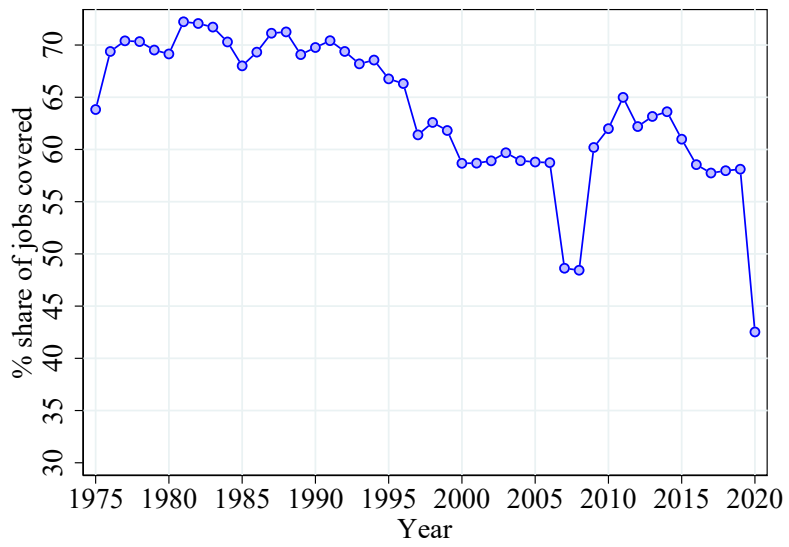

(b) \% share covered by ASHE

Notes: $1 \%$ full count is total count of employee jobs according to ONS. Includes multiple job holders. Panel (b) is derived from two series in panel (a).

Source: ASHE, ONS using Employer surveys, Labour Force Survey and administrative sources (A01 Labour market statistics summary data tables) 


\section{Additional tables and figures for Section 4}

Table 13: Hours changes in the 2020 recession

\begin{tabular}{|c|c|c|c|c|c|c|}
\hline & (1) & (2) & (3) & (4) & (5) & (6) \\
\hline 2020 & $\begin{array}{c}-0.007^{* * *} \\
(0.00)\end{array}$ & $\begin{array}{l}0.015 \\
(0.01)\end{array}$ & $\begin{array}{c}-0.007^{* * *} \\
(0.00)\end{array}$ & $\begin{array}{c}-0.009^{* * *} \\
(0.00)\end{array}$ & $\begin{array}{c}-0.007^{* * *} \\
(0.00)\end{array}$ & $\begin{array}{c}-0.008^{* *} \\
(0.00)\end{array}$ \\
\hline $2020 \times$ Female & $\begin{array}{l}0.000 \\
(0.00)\end{array}$ & & & & & \\
\hline \multicolumn{7}{|l|}{ Age: } \\
\hline $25-34 \times 2020$ & & $\begin{array}{c}-0.018^{*} \\
(0.01)\end{array}$ & & & & \\
\hline $35-44 \times 2020$ & & $\begin{array}{c}-0.021^{* *} \\
(0.01)\end{array}$ & & & & \\
\hline $45-54 \times 2020$ & & $\begin{array}{c}-0.022^{* *} \\
(0.01)\end{array}$ & & & & \\
\hline $55-64 \times 2020$ & & $\begin{array}{c}-0.021^{* *} \\
(0.01)\end{array}$ & & & & \\
\hline 2020 & & & $\begin{array}{c}0.000 \\
(.)\end{array}$ & & & \\
\hline $2020 \times$ Public & & & $\begin{array}{c}-0.009^{* * *} \\
(0.00)\end{array}$ & & & \\
\hline $2020 \times$ Union & & & $\begin{array}{c}0.009^{* * *} \\
(0.00)\end{array}$ & & & \\
\hline \multicolumn{7}{|l|}{ Firm size: } \\
\hline $100-499 \times 2020$ & & & & $\begin{array}{l}-0.003 \\
(0.00)\end{array}$ & & \\
\hline $500-1999 \times 2020$ & & & & $\begin{array}{l}-0.001 \\
(0.00)\end{array}$ & & \\
\hline $2000+\times 2020$ & & & & $\begin{array}{l}0.005^{*} \\
(0.00)\end{array}$ & & \\
\hline Skill: & & & & & & \\
\hline Mid × 2020 & & & & & $\begin{array}{l}0.003 \\
(0.00)\end{array}$ & \\
\hline High $\times 2020$ & & & & & $\begin{array}{l}-0.002 \\
(0.00)\end{array}$ & \\
\hline Earnings: & & & & & & \\
\hline $\mathrm{Q} 2 \times 2020$ & & & & & & $\begin{array}{l}0.001 \\
(0.00)\end{array}$ \\
\hline $\mathrm{Q} 3 \times 2020$ & & & & & & $\begin{array}{l}0.000 \\
(0.00)\end{array}$ \\
\hline Q4 × 2020 & & & & & & $\begin{array}{l}0.001 \\
(0.00)\end{array}$ \\
\hline Q5 $\times 2020$ & & & & & & $\begin{array}{l}0.004 \\
(0.00)\end{array}$ \\
\hline Constant & $\begin{array}{c}0.007^{* * *} \\
(0.00)\end{array}$ & $\begin{array}{c}0.102^{* * *} \\
(0.00)\end{array}$ & $\begin{array}{c}0.014^{* * *} \\
(0.00)\end{array}$ & $\begin{array}{c}0.014^{* * *} \\
(0.00)\end{array}$ & $\begin{array}{c}0.020^{* * *} \\
(0.00)\end{array}$ & $\begin{array}{c}0.032^{* * *} \\
(0.00)\end{array}$ \\
\hline Dep var mean & 0.010 & 0.010 & 0.010 & 0.010 & 0.010 & 0.010 \\
\hline R-squared & 0.000 & 0.010 & 0.001 & 0.000 & 0.002 & 0.004 \\
\hline $\mathrm{N}$ & 417,035 & 417,035 & 417,035 & 417,035 & 381,482 & 325,200 \\
\hline
\end{tabular}

Notes: $* \mathrm{p}<0.1, * * \mathrm{p}<0.05, * * * \mathrm{p}<0.01$. Outcome variable is one-year change in log hours worked. Sample held fixed for columns (1) - (4). Sample is lower in columns (5)-(6) d 48 to missing variables. Standard errors clustered by worker. Years 2010-2020.

Source: ASHE 